2017-09-23

\title{
Abnormal repetitive behaviours in captive birds: a Tinbergian review
}

Mellor, E

http://hdl.handle.net/10026.1/10137

10.1016/j.applanim.2017.09.011

Applied Animal Behaviour Science

Elsevier

All content in PEARL is protected by copyright law. Author manuscripts are made available in accordance with publisher policies. Please cite only the published version using the details provided on the item record or document. In the absence of an open licence (e.g. Creative Commons), permissions for further reuse of content should be sought from the publisher or author. 


\section{Abnormal repetitive behaviours in}

\section{captive birds: a Tinbergian review}

3

Emma Mellor* ${ }^{*}$, Ben Brilot ${ }^{2}$, Sarah Collins ${ }^{2}$

4

${ }^{1}$ School of Veterinary Sciences, University of Bristol, Langford, Bristol. BS40 5DU UK

5

${ }^{2}$ School of Biological and Marine Sciences, University of Plymouth, Drakes Circus,

6 Plymouth. PL4 8AA UK

7

8

*Corresponding author email address: em15953@bristol.ac.uk

9

Sarah Collins: sarah.collins@plymouth.ac.uk

10

Ben Brilot: ben.brilot@plymouth.ac.uk

11

12

Keywords: bird welfare; abnormal repetitive behaviour; causation; development; evolution;

13 function. 
17 Abnormal repetitive behaviours (ARBs) are associated with past, or present, welfare problems and are common elements of the behavioural repertoire of some captive animals, including birds. Millions of birds from thousands of species are held in various captive settings, yet most avian ARB research to-date focuses on just a handful of these. Therefore, our knowledge of ARBs and, by implication, welfare, of a taxonomically diverse range of avian species is poorly understood. The purpose of this review is to begin to address this by providing a useful overview of ARBs across captive avian species. Taking advantage of the research effort on well-studied species, we pool current findings relating to avian ARBs into a coherent framework, highlight gaps in understanding, and use this to give a reference point for future research in both these and other species. We adopt Tinbergen's 'Four Questions' approach to comprehensively consider ARBs from each of his four perspectives. We begin with presenting studies on ARB development, describe how physiological predispositions and early-life housing and experiences impact ARB risk in later life. Next we outline internal causal triggers for ARBs, such as the effects of neurotransmitters, hormones, and dietary deficiencies, and discuss external, environmental triggers for ARBs. In the evolution section, we detail the influence of species' evolutionary history on ARB, and use findings from early molecular studies on laying hens to discuss heritability and genes associated with ARB. The benefits of using cross-species studies to determine underlying evolutionary drivers of ARBs are also illustrated with an example from Psittaciformes. In discussing ARB 'function', we make two tentative suggestions for potential examples of ARB performance allowing a bird to cope, and also consider situations where ARB may be functionless. We then summarise, and discuss, these four interacting perspectives on avian ARBs. To finish, the benefits of Tinbergen's approach are shown in a worked example of an ARB in one species, demonstrating how this valuable framework leads to the most complete understanding of ARB. Thus, by utilising Tinbergen's Four Questions, our review provides a platform for future 
42 research on avian ARBs, to lead to a better understanding of ARBs in both well- and poorly43 studied species, and to solutions/preventive measures to improve avian welfare.

44 


\section{Introduction}

Abnormal repetitive behaviours (ARBs) are a common element of the behavioural repertoire of some captive animals (Mason, 1991b; Garner and Mason, 2002). Here, we use 'ARB' to encompass highly repetitive and invariant 'stereotypies' (Ödberg, 1978; Mason, 1991b) and more variable compulsive/impulsive behaviours like feather-pecking/plucking (reviewed by: Garner, 2006). ARBs are associated with past or present welfare problems (Mason, 2006b), such as the experience of impoverished environments (Hediger, 1950; Morris, 1964; Carlstead, 1998), or when highly motivated behaviours cannot be performed (e.g. in mice, Mus musculus: Würbel, Stauffacher \& von Holst, 1996). Performance of ARB can both reflect and exacerbate poor welfare situations; for example, pacing in captive Carnivora sometimes causes abrasions, sores and abscesses (Morris, 1964; Meyer-Holzapfel, 1968; Mason, 1991a). ARBs also cause problems for animal-human interactions: ARBperformance is generally negatively perceived (e.g. in zoo animals: Miller, 2012), reduces the desirability of companion animals (ARB can result in pet relinquishment: Marston et al., 2004; Gaskins, 2011), and can reduce the monetary value of animals (e.g. horses, Equus caballus, with ARB: McBride and Long, 2001).

ARBs in mammals have been well documented and reviewed (e.g. Bashaw, Tarou, Maki \& Maple, 2001; Benhajali, Exxaouia, Lunel, Charfi, \& Hausberger, 2014; Clubb \& Mason 2007; Mason, 1991; Sahakian, Robbins, Morgan, \& Iverson, 1975), but the same is not true for most avian species (but see: van Hoek and Ten Cate, 1998). Millions of captive birds from thousands of species are housed in zoos (Conde et al., 2011), used for research purposes (annually, approximately 151,000 - 215,000 passerines: Bateson and Feenders, 2010), farmed for food (worldwide, an estimated 9.5 billion laying hens, Gallus gallus domesticus, and 71 billion broilers were produced in 2014: FAO, 2014), and as pets (e.g. in North America there are around 10 million pet parrots: Tweti, 2008). Despite this, the vast majority 
of published literature is biased towards two species, domestic chickens, and European starlings, Sturnus vulgaris, and one order: Psittaciformes (parrots). Knowledge surrounding avian ARBs and, implicitly, welfare across this taxonomically diverse range of species remains currently limited to issues specific to these species. To address these issues, a holistic consideration of avian ARBs, permitting clear, broad predictions about susceptibility, amelioration and impact, across species and situations is now required.

The purpose of this review, therefore, is to provide a useful overview of ARBs across captive birds, taking advantage of the research effort on well-studied species, to give a starting point for future research. Tinbergen (1963) advocated that a comprehensive understanding of behaviour is only possible via a framework of posing 'Four Questions' (see also: Bateson and Laland, 2013). Thus, this review will follow his framework. Firstly, we address the proximate questions: development (how has the individual's ARB developed over time?), and causation (what are the internal and/or external mechanisms that trigger ARB?) (Mayr, 1961; Klopfer and Hailman, 1972). Next, we consider the ultimate questions: evolution (how can evolutionary history and genetics shape ARB?), and function (what is the value, if any, of ARB to the individual?) (Mayr, 1961; Klopfer and Hailman, 1972).

\section{ARBs in birds}

Table 1 summarises avian ARBs reported in the literature, loosely grouped based on similarities in outward form. Whether the superficial resemblance of some ARBs across different species is underpinned by shared causality is an important question that should be addressed in the future. Presently, however, there is not sufficient information to take an informed approach, an issue which further emphasises the need for this review. Therefore, our groupings are based on physical similarity and, importantly, do not imply similarity of development, causation, evolution or function (though we do not discount that future work might demonstrate such homologies). 
Table 1. Table summarising ARBs performed by various species of captive bird. Note that we have loosely grouped ARBs by the outward physical appearance of the ARB itself for convenience only. Our schema should not be taken to imply between-species similarity in causation, development, evolution or function: we encourage others to refute or provide future evidence for the existence of such similarities. Additionally, we anticipate that ARB is not restricted to these species and forms we give here, but until such reports are published we are limited to the examples we provide below.

\section{Specific definitions or descriptions of ARB}

\section{Affected species reported}

\section{Feather-directed ARBs}

FDB: bird repetitively chews, bites, and/or plucks out its feathers, usually self-directed, but occasionally aimed at cage-mates (van

Zeeland et al., 2009)

Feather-pecking: can be divided into two subtypes. Gentle feather pecks: nibbling and pecking without removal of the feather (Dixon et al., 2008; Dalton et al., 2013), suggested to relate to normal exploratory pecking of conspecifics (Riedstra and Groothuis, 2002). Can be 'stereotyped' in form when performed a rapid rate repeatedly at one location of the recipient (Newberry et al., 2007; Rodenburg et
Psittaciformes (Meehan et al., 2003; van Zeeland et al., 2009;

McDonald Kinkaid, 2015)

Domestic chickens, Gallus gallus domesticus, layers and broiler breeders (Savory, 1995; De Jong and Guémené, 2011)

Red jungle fowl, Gallus gallus (Jensen et al., 2005)

Pheasants, Phasianus colchicus (Butler and Davis, 2010)

Turkeys, Meleagris gallopavo (Dalton et al., 2013)

Domestic ducks, Anas platyrhynchos domesticus (Rodenburg et al., 
al., 2013). Severe feather pecks: painful pulling or removal of the feather (McAdie and Keeling, 2002; Newberry et al., 2007; Dixon et al., 2008; Rodenburg et al., 2013). Clearly feather-pecking, notably the severe form, compromises the welfare of the recipent, but it also indicates that the welfare of the performer has been compromised, either currently and/or previously (e.g. Bolhuis et al., 2009; Brunberg et al., 2016).

'Excessive' feather-plucking (Harvey et al., 2002)

Feather-picking: bird aggressively pecks at the feathers from the back and tail areas of pen-mates (Samson, 1996)
2005; Gustafson et al., 2007)

Muscovy ducks, Cairina moschata (Rodenburg et al., 2005;

Gustafson et al., 2007)

Ostriches, Struthio camelus (Samson, 1996)

\section{Locomotor ARBs: repetitive patterns of identical locomotion}

Route-tracing: repetitive tracing of a route within the cage. May include the perch, floor, cage walls, as well as airborne elements (Keiper, 1969; Garner et al., 2003; Meehan et al., 2004; Feenders and Bateson, 2012)
Psittaciformes (Meehan et al., 2004; McDonald Kinkaid, 2015)

Laying hens (Duncan and Wood-Gush, 1972)

Blue tits, Cyanistes caeruleus (Garner et al., 2003)

Marsh tits, Poecile palustris (Garner et al., 2003) 
European starlings, Sturnus vulgaris (Feenders and Bateson, 2012)

and/or

Pacing: moving forwards and back linearly along the ground, usually next to a cage wall or fence (Duncan and Wood-Gush, 1972; Degen et al., 1989; Glatz, 2000; Meehan et al., 2004)
Canaries, Serinus canaria domestica (Keiper, 1969)

Green singing finches, Serinus mozambicus (Keiper, 1969)

Gray singing finches, Serinus leucopygius (Keiper, 1969)

Blue jays, Cynanocitta cristata (Keiper, 1969)

Slate coloured juncos, Junco hyemalis (Keiper, 1969)

Tree sparrows, Spizella arborea (Keiper, 1969)

Zebra finches, Taeniopygia guttata (Jacobs et al., 1995)

Emus, Dromaius novaehollandiae (Glatz, 2000)

Ostriches (Degen et al., 1989)

Japanese quails, Coturnix japonica (Saint-Dizier et al., 2008;

Laurence et al., 2015)

Somersaulting: repeated completion of a backward aerial flip, with the European starlings (Feenders and Bateson, 2012) legs passing above the bird's head (Feenders and Bateson, 2012) *

Other locomotor ARBs: repetitive patterns of identical partial or whole-body locomotor movements 
et al., 2004; McDonald Kinkaid, 2015)

Behavioural star-gazing: bird continually lifts the head up and back

Ostriches (Samson, 1996)

towards the spine (seemingly unrelated to a similar action induced by

thiamine deficiency in poultry) (Samson, 1996)

\section{Oral ARBs: repetitive patterns of identical oral movements}

Wire-chewing, sham-chewing, food manipulation, dribbling (Meehan

Psittaciformes (Meehan et al., 2004; McDonald Kinkaid, 2015;

et al., 2004; McDonald Kinkaid, 2015; Polverino et al., 2015)

Polverino et al., 2015)

Spot-picking/pecking: bird repeatedly touches the tip or the side of its

Broiler breeders (D'Eath et al., 2009)

beak, or pecks, either itself or objects such as empty feeders, walls

Canaries (Keiper, 1969)

and drinkers (Keiper, 1969; D'Eath et al., 2009)

Green singing finches (Keiper, 1969)

Gray singing finches (Keiper, 1969)

Blue jays (Keiper, 1969)

Japanese quails (Castagna et al., 1997)

${ }^{*}$ The following ARBs appear to be functionally related to somersaulting in European starlings. Head tilt: the bird tilts its head back and the beak breaks the vertical plane (Brilot et al., 2009). Loop: very similar to a somersault, but the bird briefly clings to the cage ceiling, wall or perch with its feet. Fall: bird 'falls' backwards off its perch. Back-flip: movement on the floor resembling a somersault but minus the loop component (Feenders and Bateson, 2012). 
Regarding feather-pecking (FP) in chickens, there are two forms commonly reported in the literature: severe and gentle (see Table 1). Herein, we indicate specific form if it has been reported, though this has not been always possible as authors do not always discriminate between the two (practically, this can be difficult for large flocks of birds). As will be seen, the two forms of FP have different welfare implications (e.g. McAdie and Keeling, 2000), and cases in which the two are pooled complicates the understanding of the basis for each. For this reason, we strongly encourage researchers during future studies to discriminate between the two forms of FP wherever possible.

\section{${ }^{* * *}$ TABLE 1 ABOUT HERE, PLEASE***}

\subsection{Development}

Development examines behavioural development over an individual's lifetime. Past experiences, life-stage (i.e. chick, juvenile, and adult), and hormonal and physiological profile all shape behaviour and susceptibility to ARB development.

\subsubsection{Developmental trajectory of ARB}

Several longitudinal studies have demonstrated the developmental trajectory of FP in laying hens (Huber-Eicher and Sebö, 2001; Lambton et al., 2010; Gilani et al., 2013). There is generally good agreement across studies that the prevalence and rates of the more damaging, severe FP increases as hens age, e.g. from $27 \%$ and 0.4 bouts per bird per hour during rear, to $65 \%$ and 1.9 bouts per bird per hour during lay (Gilani et al., 2013). The developmental trajectory of gentle FP is different, however, and either does not change or declines (e.g. Lambton et al., 2010; Gilani et al., 2013); supporting the argument that gentle and severe FP are different behaviours, with different welfare outcomes.

Although FP development is perhaps the best studied avian ARB, two longitudinal studies on orange-winged Amazon parrots, Amazona amazonica examined the development of several 
119 ARBs in this species (Meehan et al., 2004). Two groups of birds, raised identically (captive120 bred and parent-reared), were observed for 48 weeks from the age of 18 -weeks. Whilst all 121 were housed individually, 'enriched' parrots received foraging and physical enrichments, whereas 'control' parrots did not (Meehan et al., 2004). Control parrots developed oral and locomotor ARBs significantly sooner and more severely than enriched parrots, especially during the first 16 weeks (Meehan et al., 2004). While it is expected that ARBs increase during development if conditions remain unchanged, improving the environment, as demonstrated in this study, can slow their development. Hence, control parrots' ARBs were significantly reduced when the enrichments were later provided (Meehan et al., 2004). Using the same experimental set up as above, this research group also reported a similar reduction in feather-damaging behaviour (FDB, see Table 1 for a description), again though enrichment provision (Meehan et al., 2003b).

\subsubsection{Physiological development and ARBs}

\subsubsection{Sex}

In some species, female birds are at increased risk of feather-directed behaviours, such as FP and FDB (Jensen et al., 2005; Garner et al., 2006; Mellor, 2014). For instance, 18\% of females versus $7.9 \%$ of males feather-pecked in a red-jungle fowl, Gallus gallus, $\mathrm{X}$ white leghorn (a laying strain) population (Jensen et al., 2005), and female parrots are more FDB prone (McDonald Kinkaid et al., 2013; Mellor, 2014). Causal factors behind this female-bias are detailed in Section 2.2.1.3, but briefly the onset of lay (and associated rises in progesterone and oestrogen) is a key time in FP development (Hughes, 1973). The same is suggested to be true in FDB (Wedel, 1999), though experimental evidence for this is currently lacking. 


\subsubsection{Personality and stress response style}

143 Personality, defined as consistent behavioural differences between individuals of the same 144 species (Nettle and Penke, 2010), also relates to ARB. Orange-winged Amazon parrots with 145 FDB showed more neuroticism-type personality traits, such as 'fearfulness' and 'excitability', 146 whereas extraversion-type traits were negatively associated with locomotor ARBs (Cussen 147 and Mench, 2015). The authors suggested personality influences an individual's susceptibility to environmental stressors, here during enrichment deprivation, and thus ARB

149 (Cussen and Mench, 2015).

150 Stress response style, or 'coping' style, a set of consistent behavioural and physiological responses to stress (Koolhaas et al., 1999), also affects susceptibility to ARB development. Two response styles are recognised, each with distinctive behaviours and physiological characteristics. 'Proactive' individuals have an active behavioural stress response, are 'bold' (e.g. will approach unfamiliar objects, sensu: Wilson et al., 1994), aggressive, impulsive, and are inclined towards routine formation (Koolhaas et al., 1999). 'Reactive' individuals have a passive behavioural stress response, are 'shy' (e.g. unlikely to approach unfamiliar objects, sensu: Wilson et al., 1994), are less aggressive, avoid risks, and behave flexibly (Koolhaas et al., 1999). Proactive individuals are characterised by low hypothalamus-pituitary-adrenal axis responsiveness and high sympathetic reactivity, whereas the opposite occurs in reactive individuals (Koolhaas et al., 1999). These differences in response style are suggested to predispose proactive individuals to ARB development (Koolhaas et al., 1999;

162 Ijichi et al., 2013) with neurobiological differences being particularly influential (detailed in 163 Section 2.2.1.2).

164 There are two avian examples of proactive susceptibility to ARB. Two strains of white 165 leghorn chicken with contrasting propensity to FP also show differential response styles: high FPs tend to be proactive, and low FPs reactive (Blokhuis and Beutler, 1992; van

167 Hierden et al., 2002a; van Hierden et al., 2002b). In African grey parrots, Psittacus erithacus, 
van Zeeland et al. (2013b) found some indication that parrots with FDB may have a proactive response style, but this was not consistent across different experiments. FDB status did not predict response style during a stressful event (manual restraint), but during novel object and open field tests parrots with FDB adopted a proactive style (van Zeeland et al., 2013b), i.e. they were bolder, and more likely to approach a novel object and explore during an open field test than birds without FDB.

\subsubsection{Past experiences and ARBs}

\subsubsection{Rearing conditions}

Rearing conditions experienced during early life influence ARB development. In laying hens, brooded (hen-reared) chicks are at less risk of developing FP when older (Perré et al., 2002) and are less likely to suffer FP and cannibalism-related mortality (Riber et al., 2007). Handreared African grey parrots (from 5 weeks old or less) are at increased risk of ARB as adults and are also more aggressive towards humans (Schmid et al., 2006). Contrastingly, though not directly comparable as all parent-reared birds were also wild-caught, hand-reared European starlings are less likely to perform somersaulting and other ARBs (Feenders and Bateson, 2012; but see: Coulon et al., 2014), are less fearful of humans (Feenders and Bateson, 2011), and do not show any indications of compromised cognitive function (Feenders and Bateson, 2013). As European starlings do not readily breed in captivity (Bateson and Feenders, 2010), whether this effect is one of hand-rearing or origin (wild versus captive) is unknown.

While not totally clear-cut in some cases, wild-caught birds may be more likely to develop ARBs than captive-bred. Wild-caught African grey parrots are more likely to display FDB than captive-bred individuals, regardless of captive-rearing technique (Schmid et al., 2006). Similarly, Keiper (1969) found his wild-caught blue jays, Cyanocitta cristata, performed more route-tracing but less spot-picking than captive-raised counterparts. This blue jay example 
suffers from the same confound as with the starlings, as captive-raised birds were all handreared, leaving it impossible to judge the most influential developmental factor.

Aside from parental contact, other appropriate conspecific social experiences can be important to young birds. Solitary- and hand-reared captive Hawaiian crows, Corvus hawaiiensis, show more ARB as adults compared with group-raised birds. They also display other behavioural problems such as impaired social skills, particularly towards mates (Harvey et al., 2002). Similarly, significant between-group behavioural differences were reported in young orange-winged Amazon parrots housed for a year in enriched cages, either individually or with a same-sex partner (Meehan et al., 2003a). None of the pairhoused parrots developed ARBs, yet $57 \%$ of the single-housed birds developed oral and/or locomotor ARBs, had a more restricted behavioural repertoire, were less active and more fearful: clearly demonstrating the importance of a cage-mate to the welfare of these birds (Meehan et al., 2003a). From these examples, it seems clear that parental/maternal and/or conspecific social contact whilst young is influential in avian behavioural development, including that of ARB.

\subsubsection{Previous housing conditions}

The experience of pecking or foraging opportunities during early life influences FP development in adult laying hens. For example, housing chicks on litter has been repeatedly shown to reduce FP or its effects at adulthood (Blokhuis and van der Haar, 1989; Bestman et al., 2009; Tahamtani et al., 2016), with even a short experience of litter protective against

213 FP development to some degree (10 days: Nicol et al., 2001). Scattering grain in the litter

214 (Blokhuis and van der Haar, 1992) and providing straw and objects to encourage pecking

215 during rear can result in less FP when birds are older (notably, severe FP in turkeys, Meleagris gallopavo: Martrenchar et al., 2001). In these examples, lack of appropriate foraging and exploratory opportunities and/or other stimuli during rear may result in 
218 redirection of pecks towards flock-mates' feathers (e.g. Martrenchar et al., 2001; Bestman et 219 al., 2009).

220 Experiencing and consuming loose feathers in the rearing environment may be a key risk factor for severe FP in laying hens. Hens moult three times during rear, so loose feathers are plentiful (Appleby et al., 1992). However, a relative shortage of loose feathers is then experienced during lay, resulting in pecking attention being redirected towards feathers still attached to flock-mates (McKeegan and Savory, 1999; Ramadan and von Borell, 2008). By regularly removing feathers from the rearing environment, Ramadan and von Borell (2008) demonstrated that hens who do not experience plentiful loose feathers during development are less likely to develop severe FP. Therefore, for laying hens 'learning' to peck at feathers when young seems a key developmental step for FP at later life.

\subsection{Causation}

230 The causation of behaviour or, as preferred by some, mechanism of control (Bateson and 231 Laland, 2013) refers to internal and external stimuli triggering its performance. For internal 232 triggers, we include the effects of neurotransmitters, hormones, brain function, and comorbidity with medical conditions. The current environment can be an external trigger for ARB, but separating out the effects of current and previous environments is problematic, though not a problem unique to ARB (Tinbergen, 1963; Bateson and Laland, 2013). To this end, ARB can be a 'scar' of welfare problems past and not necessarily indicative of the animal's current environment and welfare (sensu: Mason and Latham, 2004). To deal with this, we have limited ourselves in all but one example (Section 2.2.4.1) to discussing clear current environmental triggers for ARB. 


\subsubsection{Internal triggers for ARB}

241

242

243

244

245

246

247

248

249

250

251

252

253

254

255

256

257

258

259

260

261

262

263

264

\subsubsection{Neurotransmitters}

The neurotransmitters dopamine (DA) and serotonin (5-hydroytryptamine, 5-HT), act in the direct and indirect neural pathways responsible for behaviour modulation (reviewed by: Garner, 2006), and are linked with ARB. Generally, ARBs are reduced through activation of the indirect or suppression of the direct pathway, demonstrated experimentally by administration of dopaminergic and serotonergic drugs (Langen et al., 2011). For instance, apomorphine, a $D_{1}$ and $D_{2}$ receptor agonist (van Hierden et al., 2005) induced object-pecking in male Japanese quail, Coturnix japonica (Castagna et al., 1997), and male laying chicks (Machlis, 1980), while Kjaer et al. (2004) reduced FP in laying hens with haloperidol, a $D_{2}$ receptor antagonist. Similarly, a 5- $\mathrm{HT}_{1 \mathrm{~A}}$ receptor agonist that reduces $5-\mathrm{HT}$ synthesis increased severe FP in high FP line laying chicks (also see Section 2.2.1.2: van Hierden et al., 2004a), whereas dietary supplementation of a 5-HT precursor, tryptophan, stimulated serotonergic neurotransmission and reduced FP in young laying chickens (Savory, 1998; Savory et al., 1999; van Hierden et al., 2004b). Finally, dependent upon the drug used and receptor affected, oral ARBs in broiler breeders - the parent stock of meat chickens - were either suppressed or induced with various $5-\mathrm{HT}_{1 \mathrm{~A}}, 5-\mathrm{HT}_{2}$ and $5-\mathrm{HT}_{3}$ receptor agonists and antagonists (Koštál and Savory, 1995). Altogether, increased DA activity is associated with increased ARB, but the relationship between ARBs and 5-HT function seems complex and receptor-specific, perhaps reflective of interactions between the two systems (sensu: Langen et al., 2011).

Neurotransmitter deficiencies are also suggested to be causal in FDB in parrots (van Zeeland et al., 2009), but experimental studies confirming this are lacking. Limited reduction in FDB using DA and 5-HT antagonist drugs do provide some cautious, anecdotal support for this (though sample sizes were small, two and 12 birds, respectively: Iglauer and Rasim, 
1993; Mertens, 1997). Rigorous experimental research is therefore now required to investigate relationships between DA, 5-HT and FDB.

\subsubsection{Neurotransmitters and interaction with stress response style}

As mentioned in Section 2.1.2.2, proactive animals are suggested to be predisposed to ARB development due to response style-specific differences in 5-HT and DA activity (Koolhaas et al., 1999; ljichi et al., 2013) and sensitivity to manipulations of these systems (van Hierden, 2003). In line with this, proactive high FP laying chicks were more sensitive to the effects of a $D_{1}$ and $D_{2}$ receptor agonist (measured by increased hyperactive locomotion) (van Hierden et al., 2005). More support comes from a study that increased severe FP in high FP laying chicks by reducing $5-\mathrm{HT}$ synthesis with a $5-\mathrm{HT}_{1 \mathrm{~A}}$ receptor agonist, yet observed no effect in low FP chicks (van Hierden et al., 2004a). Similarly, a significant reduction of gentle FP via dietary tryptophan supplementation was only found in high FP laying chicks (van Hierden et al., 2004b). The predicted relationship between response style (based on FP) and 5-HT and DA activity is not unequivocal, however. Variation is observed across life-stages (Buitenhuis et al., 2006; Kops, et al., 2017) and across different lines (i.e. whether purposefully selectively bred based on FP (Kops et al., 2017), or not (van Hierden et al., 2002b)), leaving the response style - ARB relationship a little unclear.

\subsubsection{Hormones}

The onset of lay in laying hens is a key time in FP; experimental manipulation of progesterone and oestrogen demonstrates the influence of these hormones (Hughes, 1973). 12-week old pullets received sex hormone releasing implants with un-implanted pullets used as controls (Hughes, 1973). By 18 weeks, progesterone and oestrogen together resulted in a large increase in FP, progesterone alone induced a lesser, but still significant, increase, and the usual dramatic onset of lay increase in FP was suppressed with testosterone administration from 18-24 weeks (Hughes, 1973). Given similarities in outward forms of FP 
and FDB and the female-bias (Garner et al., 2006; Mellor, 2014) it is reasonable to predict

291 FDB may be similarly affected by hormonal control, a testable hypothesis.

292

293

294

295

296

297

298

299

300

301

302

303

304

305

306

307

308

309

310

311

312

313

314

315

\subsubsection{Nutrient deficiencies and hunger}

In laying hens, deficiencies in certain nutrients trigger exploratory behaviour, including pecking. These deficiencies are therefore implicated in FP (Kjaer and Bessei, 2013). This has been extensively reviewed elsewhere (e.g. van Krimpen et al., 2005; Kjaer and Bessei, 2013) so, aside from fibre, only a brief overview is provided here. Deficiencies in crude protein (e.g. Ambrosen and Petersen, 1997) and specific amino acids such as methionine (e.g. Harms and Russell, 1996; Elwinger et al., 2008), arginine (e.g. Sirén, 1963), and lysine (e.g. Quentin et al., 2005) have been linked to FP, which is quickly and effectively reduced when appropriate diets are fed (Kjaer and Bessei, 2013). Fibre positively affects gut motility, and increases satiety levels (Hetland et al., 2004; Rodenburg et al., 2013); inadequate provision of fibre is associated with severe FP (van Krimpen et al., 2009; Rodenburg et al., 2013). Ingested feathers act on the gut in a similar fashion to fibre, thus by consuming feathers birds may increase satiety (Harlander-Matauschek et al., 2006b). Interestingly, the morphology of severe FPs (though not gentle FPs) is similar to foraging pecks, indicating the likely motivational basis of severe FP (Dixon et al., 2008). FP followed by feather-eating, therefore, may allow the birds to meet a dietary and digestive need not provided by the diet (Rodenburg et al., 2013).

While FP is more commonly reported in laying strains, it is also reported in broiler breeders (de Jong and Guémené, 2011) and relates to hunger (Morrissey et al., 2014a). Strong artificial selection in broilers means birds can effectively reach slaughter weight through rapid weight gain; this weight gain and subsequent obesity damages long-term health and productivity of broiler breeders, especially females (Richards et al., 2010). To avoid this, broiler breeders are usually restricted to $25-50 \%$ of ad libitum intake (Savory et al., 1993; Renema et al., 2007), show signs of chronic hunger (Mench, 2002), and physiological 
316 indications of stress, indicating that such restriction is detrimental to welfare (e.g. Hocking et

317 al., 1993; de Jong et al., 2002). Furthermore, feed-restriction and hunger are associated with

318 FP and oral ARBs such as spot-pecking (Sandilands et al., 2006; D'Eath et al., 2009;

319 Nielsen et al., 2011; Morrissey et al., 2014a; Morrissey et al., 2014b). To reduce hunger and 320 improve welfare, studies have investigated the effects of 'alternative' diets. Alternative diets

321 are typically qualitative-restrictive (high volume, low quality and energy) diets, prolonging

322 feeding times, and/or contain appetite suppressants (e.g. calcium propionate) to reduce

323 feeding motivation (e.g. Sandilands et al., 2006). These alternative diets are often, though

324 not always, associated with positive behavioural indicators of welfare such as a reduction in

325 FP and its effects, and more 'normal' foraging behaviour overall (reviewed by: Tolkamp and

326 D'Eath, 2016). For example, Morrissey et al., 2014a; 2014b found feather condition was

327 better in hens fed alternative compared with control diets. However, alternative diets are

328 controversial due to uncertainties surrounding their welfare effects and whether underlying

329 'metabolic hunger' for nutrients and energy is actually satisfied (see: Tolkamp and D'Eath, 330 2016).

\section{$331 \quad$ 2.2.2 Medical conditions and ARBs}

332 ARB is co-morbid with some avian medical conditions. Escherichia coli infections (Brunberg 333 et al., 2016), intestinal worm related mortality rates, infectious bronchitis, and egg peritonitis 334 are linked with FP in laying hens (Pötzsch et al., 2001). As damaged feathers can be visual 335 cues for FP (Hughes, 1985; McAdie and Keeling, 2000), perhaps in some of these examples the altered appearance (including feathers) and behaviour of ill birds has a likewise effect. In parrots, FDB may coincide with endoparasite (e.g. Giardia psittaci, an intestinal protozon:

338 Clyde and Patton, 1996; Doneley, 2009) and ectoparasite infections (e.g. quill mites,

339 Syringophilus spp. Doneley, 2009), presumably irritating the skin and/or feathers, causing

340 the bird to chew at or remove them. This is also the case with painful and/or irritating

341 diseases (renal and liver disease: Jaensch, 2000; Burgos-Rodríguez, 2010; van Zeeland 
and Schoemaker, 2014). In these instances, FDB may be localised to the painful area (e.g.

343 in the synsacrum in parrots with renal disease: Burgos-Rodríguez, 2010), or generalised

344 (van Zeeland and Schoemaker, 2014).

345 It should be noted that the examples given here are correlative and, in some cases, anecdotal only, i.e. causation cannot be inferred. There could be causal mechanism linking ill-health and $A R B$, or poor environmental conditions may be the underlying causal factor for both. Experimental manipulations may aide this distinction. By experimentally administering young laying hens with an immune challenge, Parmentier et al., (2009) showed a link between feather condition and immune response. Poorer plumage condition, and thus increased FP, was found in hens given a higher dose of human serum albumin, showing that an immune response alone is sufficient to trigger FP. While the precise causal link between immune response and FP was unclear, it neatly demonstrated the immune challenge itself was the influencing factor, providing clear direction for further work. In all these cases, however, if an ARB is just a symptom of disease, we would predict that successful disease treatment would also eliminate the ARB.

\subsubsection{CNS dysfunction and ARBs}

Altered brain function and physiology is associated with ARBs in various mammalian species, being best studied in humans (reviewed by: Garner, 2006), and is likewise suggested to be influential in some avian ARBs. ARB-related CNS dysfunction in birds can be assumed by analogy with known CNS dysfunction-induced behaviour problems in humans. Similarities between FDB and trichotillomania (plucking of hair) in humans for instance implies, as per trichotillomania, that CNS dysfunction underlies FDB (Moon-Fanelli et al., 1999; Garner et al., 2006). CNS dysfunction is also inferred experimentally, typically, by measuring perseveration. Perseveration - the inappropriate repetition of an ineffectual response - is used as a proxy for CNS dysfunction, because it may indicate problems with 
367

368

369

370

371

372

373

374

375

376

377

378

379

380

381

382

383

384

385

386

387

388

389

390

391

basal ganglia and other brain regions responsible for behaviour selection and control (Norman and Shallice, 1986; Garner, 2006). Perseveration positively correlated with ARB in orange-winged Amazon parrots (Garner et al., 2003b), blue tits, Cyanistes caeruleus, and marsh tits, Poecile palustris, (Garner et al., 2003a), and, although less definitively, in high FP laying hens (during an extinction learning task: Harlander-Matauschek et al., 2006a, but see: Kjaer et al., 2015).

Thus when perseveration is measured, overall, it does covary with ARB in birds, i.e. those performing the most ARB are the most perseverative. However, perseveration or perseverative tendencies are also linked to stress response style (sensu: Koolhaas et al., 1999; Coppens et al., 2010). The routine formation tendency of proactive individuals is due to non-pathological individual differences in brain structure (Coppens et al., 2010). Given that high FP laying hens tend to be proactive (Blokhuis and Beutler, 1992; van Hierden et al., 2002a; van Hierden et al., 2002b), if these hens are more perseverative than low FP hens, is this just a by-product of their response style? Or a sign of a dysfunctional CNS? More damningly, in humans at least, perseveration is also seen in 'normal' individuals without ARBs (e.g. Ramage et al., 1999). Therefore, it is unclear whether perseveration is a valid proxy of brain dysfunction in avian species.

\subsubsection{Environmental triggers for ARB}

Many environmental risk-factors have been identified for avian ARBs, but the causal connection between the trigger and the ARB is generally unknown.

Firstly, ARB may be triggered by discrete events. Pacing, for example, was induced in Japanese quail when novel objects were placed into the cage (Saint-Dizier et al., 2008). Likewise, and unexpectedly as prior to this only wild-caught birds had been reported to somersault, somersaulting was triggered in hand-reared starlings during an experiment investigating the potential enriching effects of videos of landscapes (Coulon et al., 2014). 
392 Similarly, the removal of a preferred environment can trigger ARB. For instance, a move

393 from large, group-housed aviaries into small single-occupancy cages quickly led to

394 somersaulting in starlings and mild FDB in an African grey parrot (Feenders and Bateson,

395 2012; van Zeeland et al., 2013a). Negative contrast effects may play a role here too (sensu:

396 Burman et al., 2008); for example, layer pullets switched from wood-shavings to slatted

397 floors performed more FP than those housed on slatted floors throughout (Blokhuis and

398 Arkes, 1984). It seems likely, given that ARBs were triggered so quickly in these examples,

399 that the birds found these events aversive.

400 Frustrated motivation of species-specific behaviours can lead to ARB. Here, when the 401 opportunity to perform the frustrated behaviour is provided, ARB should be reduced or even 402 eliminated (Mason and Latham, 2004). For example, water for bathing is important to duck 403 welfare (Jones et al., 2009), as illustrated by Riber and Mench (2008) who found FP was

404 higher in farmed Muscovy ducklings, Cairina moschata, without water access than those 405 with. Frustrated foraging motivation is often proposed to underlie oral ARBs and FDB 406 (Meehan et al., 2003b; van Zeeland et al., 2009). Supporting this are reports of increased 407 foraging times and reduced oral ARBs and FDB in canaries, Serinus canaria domestica, and 408 African grey parrots, respectively, using foraging enrichments (Keiper, 1969; Lumeij and 409 Hommers, 2008; van Zeeland et al., 2013a). More evidence comes from orange-winged 410 Amazon parrots, as enrichment provision reduced the amount of ARB performed 411 (unenriched birds performed more), but also changed the primary form of ARB (Meehan et 412 al., 2004). Enriched birds performed predominantly locomotor ARBs, whereas the mix of 413 locomotor and oral ARBs was more equal in unenriched birds (Meehan et al., 2004).

414 Interestingly, in the latter group this changed when enrichment was later provided; locomotor 415 ARBs became predominant in these birds too, implying the parrots' foraging 'needs' were 416 almost completely satisfied by the added enrichments (Meehan et al., 2004). Note that while 417 frustration would appear the most likely trigger in these examples, as ever, without careful 418 experimentation we cannot state that other causal factors were not influential. 
419 Finally, housing animals - including humans - in impoverished conditions can impair CNS

420 development, causing dysfunction (Leipoldt, 1992; Lewis et al., 2006) and ARB (Hediger,

421 1950; Morris, 1964; Carlstead, 1998). Such conditions are regularly cited as causal in avian

422 ARBs (Keiper, 1969; 1970; Jacobs et al., 1995; El-Lethey et al., 2000). Small and/or

423 unenriched cages across numerous species are associated with increased ARBs, such as

424 hopping in zebra finch, Taeniopygia guttata (Jacobs et al., 1995), oral ARBs in budgerigars,

425 Melopsittacus undulates (Polverino et al., 2015), and route-tracing in canaries, (Keiper,

426 1969). Similarly, in young orange-winged Amazon parrots barren, unenriched cages reliably

427 trigger FDB and other ARBs, which are successfully reduced with provision of physical and

428 foraging enrichments (Meehan et al., 2003b; Meehan et al., 2004; Cussen and Mench,

429 2015). As the orange-winged Amazon parrots' ARBs were so easily reduced it seems

430 unlikely that CNS dysfunction was an important causal factor; a hallmark of ARB driven by

431 CNS dysfunction is that changing to more appropriate environmental conditions is unlikely to

432 alter ARB (and may even make it worse) (reviewed by: Mason and Latham, 2004). Indeed,

433 to the best of our knowledge just one study to date on laying hens has investigated the

434 effects of different housing conditions on brain development. Patzke et al., (2009) reported

435 only minor differences in key brain areas believed to be sensitive to environmental

436 stimulation: hippocampal structures and the nidopallium caudolaterale. This somewhat

437 unexpected result could indicate the adult avian brain may be less responsive to effects of

438 environmental conditions than is that of young birds (e.g. Leitner and Catchpole, 2007;

439 Patzke et al., 2009). However, as all the hens shared similar, possibly traumatic, pre-study

440 rearing conditions, i.e. non-brooded, conditions known to affect behaviour (Edgar et al.,

4412016 ) and brain development (Nordquist et al., 2014) this early experience may have

442 influenced early brain development across all hens and thus explain their results (Patzke et

443 al., 2009). Therefore, this leaves plenty of scope to thoroughly investigate the effects of

444 impoverished housing conditions on CNS development and ARB in birds across life-stages. 
446 Here, we detail one example where causation has not been adequately established, yet, we

447 feel its implications for avian welfare warrants discussion. Two studies using survey data

448 found various psittacine species to be at increased risk of FDB if unable to fly (pet African

449 grey parrots (Schmid et al. 2006); preliminary results from 23 pet psittacine species (Mellor, 450 2014)). Causation cannot be inferred from these examples, but the results are intriguing as 451 captive flight-adapted species often have their flight restricted or entirely prevented in captivity (van Hoek and Ten Cate, 1998; Hesterman et al., 2001). Indeed, partial wingamputations did not diminish great-mynahs, Acridotheres grandis, preferences for large spaces with vertical height, implying the birds were still motivated to fly, even if not physically able (Peng et al., 2013). Preventing flight in captive birds may, therefore, represent a significant area of avian welfare concern.

\subsection{Evolution}

To understand the evolution of behaviour, Tinbergen (1963) advocated comparing the behaviour across a group related of species, and investigating the genetic control of speciesspecific behaviours. In this section, therefore, interspecific differences in ARB and heritability and genetics of ARB will be discussed.

\subsubsection{Inter-specific differences in ARB}

Phylogenetic comparative methods (PCMs) are useful in studying the evolution of behaviour, examining how it differs across a group of species and its co-evolution with other aspects of species biology and behaviour (Blumstein and Fernández-Juricic, 2010). In captive wild animal welfare studies, PCMs can be used to identify species-level risk-factors (i.e. speciestypical traits) for poor captive welfare, including ARB (Clubb and Mason, 2003; Clubb and 
Mason, 2007; Müller et al., 2011; Pomerantz et al., 2013; Kroshko et al., 2016; reviewed by: Mason, 2010).

470 Currently, McDonald Kinkaid (2015) has performed the only avian welfare PCM study, 471 uncovering two risk-factors for poor welfare in parrots. Species with naturally effortful 472 foraging modes, e.g. Ducorp's corella, Cacatua ducorpsii, were at increased risk of FDB 473 (McDonald Kinkaid, 2015). The second risk-factor was relative brain volume; species with 474 relatively large brains, e.g. red-shouldered macaws, Diopsittaca nobilis, were at increased 475 risk of oral and locomotor ARBs (McDonald Kinkaid, 2015).

\subsubsection{Intra-specific differences in ARB}

\subsubsection{Heritability}

Selective breeding in laying hens demonstrates a possible heritable component to FP (e.g. Kjaer et al., 2001). FP heritability estimates $\left(h^{2}\right)$ range from $0.07-0.54$ (Cuthbertson, 1980; Bessei, 1984; Kjaer and Sørensen, 1997), and vary further between different breeds and lines (Faure et al., 2003). These estimates are somewhat confounded by the fact that social environment, i.e. flock mates, may also play a role in accurately estimating heritability for FP damage (Brinker et al., 2014). In addition, many studies aggregate data on both types of FP in their heritability estimates. This could be an important distinction to make, for Rodenburg et al. (2003) found while gentle FP was heritable in their study $\left(\mathrm{h}^{2}\right.$ at 5 weeks of age $=0.12$; at 30 weeks $=0.15$ ), severe FP was not. Therefore, assuming the two forms of FP really do represent two distinct behaviours, establishing the heritability of each and how this varies between life-stages is important.

Within a laboratory colony of orange-winged Amazon parrots, the $\mathrm{h}^{2}$ estimate for FDB was $1.14 \pm 0.27$ (S.E.) (Garner et al., 2006). The estimate is greater than 1 as the small sample size featured full-siblings, limiting its generalisability; replication is now required with a larger, less related sample (van Zeeland et al., 2009). However, this does suggest, as with laying 
hens, it might be possible to select against FDB (Garner et al., 2006). Heritability of

494 locomotor and oral ARBs in this study was low: $h^{2}=-0.08 \pm 0.14$, though it is possible that the close relatedness, and thus little genetic variability, within their study group may explain this (Garner et al., 2006).

\subsubsection{Genes}

Molecular research has identified several genomic regions associated with FP. In adult laying hens possible quantitative trait loci (QTL), and clues of the likely location of genes for performing gentle and severe FP, were found on chromosome GGA2, and a potential one for receiving gentle FP on GGA5 (Buitenhuis et al., 2003a; 2003b). QTL locations for FP differed in 6-week old chicks though, performing gentle FP was located on GGA10, receiving gentle FP on GGA1, alongside further suggestive QTL on GGA2, 6, and 7 (Buitenhuis et al., 2003a). Biscarini et al. (2010) found good agreement with these QTL mapping studies, uncovering associations between giving and receiving FPs and single-nucleotide polymorphisms (SNPs) on many of the same chromosomes (see: Buitenhuis et al., 2003a; 2003b).

Specific gene-expression relates to FP. By comparing the genetic profiles of high and low FP laying hens, Flisikowski et al., (2009) uncovered two candidate genes associated with FP: DRD4 and DEAF1. These respectively encode for DA receptor $\mathrm{D}_{4}$ and a $5-\mathrm{HT}$ regulatory

511 factor. Emerging evidence also suggests that some high FP laying hens show hyperactivity-

512 type behaviour (Kjaer, 2009; Labouriau et al., 2009), perhaps underpinned by higher DA 513 activity and thus a more active motor-system output overall (Kops et al., 2017). While the 514 sample size was very small, Labouriau et al. (2009) reported differences in gene expression 515 between the hyperactive high FPs $(N=4)$ and more 'normal' birds $(N=56)$, notably OPRD1 516 and OPRK, which relate to the opioid system (Labouriau et al., 2009). As well as these links 517 to DA and 5-HT systems, FP is associated with genes directly and indirectly involved in 518 absorption of nutrients from the intestine, glucose homeostasis, and the immune system 
519 (Biscarini et al., 2010; Brunberg et al., 2011). Causal links between these genes and FP 520 cannot be inferred from these studies, but they do further strengthen proposed relationships 521 between FP and feeding motivation, and the DA and 5-HT systems.

522 Finally, research into the genetic profile of FP victims using white leghorn and red jungle fowl crosses, revealed a gene for feather pigmentation, PMEL17, predicted the severity of feather damage (Keeling et al., 2004). The white leghorn's dominant white allele (I) inhibits feather pigmentation, the wild-type recessive allele (i) results in some degree of feather pigmentation. Thus, recessive homozygotes (i/i) received the most FP damage, dominant homozygotes (I/I) the least, with heterozygotes (I/i) intermediate (Keeling et al., 2004). Wood-shavings in the litter were suggested to be more conspicuous on the feathers of pigmented birds, serving as a pecking stimulus (Keeling et al., 2004).

\subsection{Function}

531 In this section, the function of behaviour is considered. Generally speaking, behaviours

532 increase the fitness of the individual, be it through increasing immediate survivorship, or

533 reproductive output (sensu: Tinbergen, 1963). Where do ARBs fit into this? Common

534 definitions of ARB emphasise its seemingly 'functionless' nature (Ödberg, 1978; Wiepkema,

535 1983); in some cases it is very difficult to see how ARBs serve to benefit the animal, e.g.

536 self-damaging ARBs such as FDB leading to skin damage and infection (Meehan et al.,

537 2003b; van Zeeland et al., 2009). However, combining evidence from better-studied taxa

538 with a limited quantity of avian research, here we discuss potential functions of some specific

539 cases of $A R B$, as well as considering cases where ARB may be functionless.

\section{$540 \quad$ 2.4.1 ARB and coping}

541 ARB may calm an animal or facilitate coping with stressors. Firstly, ARB may reduce

542 physiological stress (e.g. self-injurious biting in primates reduces heart rate: Novak, 2003), or 
543 alleviate signs of pain (e.g. crib-biting provides gastric irritation relief to horses: Wickens and

544 Heleski, 2010), and is implied in FDB in parrots with renal disease (Burgos-Rodríguez,

545 2010). Additionally, ARB can be self-reinforcing ('DIY enrichments') and, as reported by

546 humans, repetition itself is stress-relieving ('mantra effects') (Mason and Latham, 2004),

547 allowing a regain of control and reduction in anxiety, especially after a stressful event (Eilam

548 et al., 2011; Lang et al., 2015). When an ARB allows an animal to cope, in the Tinbergian

549 sense "... the animal would be worse off if deprived of this attribute." (Tinbergen, 1963), ARB

550 is thus associated with an improvement in welfare when the behaviour is performed (sensu:

551 Mason and Latham, 2004).

552 Though 'coping' is widely suggested to underlie several avian ARBs (e.g. in conures,

553 Pyrrhura perlata perlata: van Hoek and King, 1997), to the best of our knowledge, this has never been formally tested. We do, however, have two tentative potential avian coping examples. The first relates to FP, and eating, caused by low fibre diets in laying hens (van Krimpen et al., 2009), whereby birds could be coping by managing a dietary and digestive need not provided by the diet (see Section 2.2.1.4). Our second 'coping' example is FDB associated with a painful disease: e.g. in parrots with renal disease (see Section 2.2.2) (Burgos-Rodríguez, 2010). In humans, stimulating certain areas of the body reduces pain via endorphin release (termed acupuncture analgesia), in itself a reinforcing act (Wang et al., 2008). Self-harming humans and self-biting rhesus macaques target many of the same

562 body areas (Wisely et al., 2002; Polanco, 2016). It is not implausible that FDB in this 563 instance could be a do-it-yourself pain relief to alleviate disease-related pain.

564 Clearly, these hypotheses require testing, and the multi-factorial nature of FP and FDB 565 means they may be coping mechanisms only under these very specific circumstances. We would predict, however, if ARB does allow the animal to cope, that indicators of improved

567 welfare would be seen, such as decreased indications of hunger post-feather consumption 568 by laying hens, and reductions in arousal, such as heart rate, during and immediately after a 
569

570

571

572

573

574

575

576

577

578

579

580

581

582

583

584

585

586

587

588

589

590

591

592

593

bout of FDB (based on: Novak, 2003), and that prevention of the ARB would negatively impact welfare (Mason and Latham, 2004).

\subsubsection{ARB and CNS dysfunction}

Finally, ARB may be indicative of an animal and its brain having been permanently altered by captivity. If perseveration is indicative of CNS dysfunction (but see Section 2.2.3) then in the perseverative orange-winged Amazon parrots, blue tits and marsh tits we may have evidence of CNS dysfunction (Garner et al., 2003a; Garner et al., 2003b). Logically we might also expect CNS changes to affect overall behaviour (sensu: Mason and Latham, 2004). Hawaiian crows may demonstrate such pervasive behavioural changes: as well as more ARB, adult crows raised in social isolation as chicks showed inappropriate play and social behaviour, especially towards mates, directly reducing reproductive output (Harvey et al., 2002). Associations between ARB and reduced reproductive success are reported in other species (American mink, Neovison vison: Díez-León et al., 2013). It therefore seems likely that signs of behavioural abnormality alongside ARB are indicative of an animal altered by captivity, with CNS pathology implicit in this. As such, for a bird with its behavioural repertoire shaped and affected by such conditions, it is most unlikely that ARB serves it any function.

\section{Discussion and conclusions}

This review has considered avian ARBs from Tinbergen's four interactive perspectives: development, causation, evolution, and function. Throughout, we have been limited to discussing a minority of representatives from this diverse taxonomic group. This does not mean absence of ARB evidence in other species equates to evidence of absence; more likely under- or non-reporting is the case. Given that thousands of avian species are held in captivity, and that the commonest captive bird species (domestic chicken) numbers in the billions, the extent of this could be far-reaching, leaving plentiful opportunities for future 
594

595

596

597

598

599

600

601

602

603

604

605

606

607

608

609

610

611

612

613

614

615

616

617

618

619

research. By reviewing different ARBs in the species discussed here, we hope this review provides a good starting point for researchers to go forward and investigate avian ARBs further, both in well-studied species and others. Below we summarise the four perspectives of avian ARBs, indicating current gaps in knowledge and directions for research.

In relation to development, female laying hens, jungle fowl, and parrots are at higher risk of FP (Jensen et al., 2005) and FDB (Garner et al., 2006; Mellor, 2014), with the onset of lay a crucial time in FP (Hughes, 1973). As evidenced in high FP laying hens (e.g. Blokhuis and Beutler, 1992) and, to a lesser extent, African grey parrots with FDB (van Zeeland et al., 2013b), birds with a proactive stress response style are more susceptible to ARB, though this now needs replication in other species. Studies on causation should be informed by knowledge of these developmental risk-factors for ARB, e.g. given the female-bias future studies might ask how sex hormones affect FDB. Additionally, the developmental trajectory of ARB is poorly described and understood in all but two species, and biased towards younger birds (e.g. Huber-Eicher and Sebö, 2001; Meehan et al., 2004). Therefore, this is a research area requiring attention, to unpick whether certain developmental windows are key to ARB at different life-stages, ARB 'treatability', and what this implies about the root cause(s) of ARB.

The rearing environment clearly influences ARB development. Providing opportunities to develop and perform highly motivated behaviours, such as foraging and environmental exploration, offers at least some protection against ARBs when older (FP: Blokhuis and van der Haar, 1989; Martrenchar et al., 2001; Nicol et al., 2001; Bestman et al., 2009; Tahamtani et al., 2016). Appropriate parental and social contact whilst young also shapes behavioural development, including ARB, in both precocial and altricial species (Harvey et al., 2002; Perré et al., 2002; Meehan et al., 2003a). However, early maternal separation and handrearing seem to be influential in ARB development in some (Schmid et al., 2006), but not all species (Feenders and Bateson, 2011; 2012; 2013). As an example, Riber et al., (2007) 
620 found that brooded layer chicks pecked the ground sooner and more often than non-brooded

621 chicks. When older, brooded chicks also performed fewer severe FPs and suffered less

622 cannibalism-related mortality than non-brooded (Riber et al., 2007).

623 Experience of wild conditions may predispose some species such as European starlings

624 (Feenders and Bateson, 2012) and blue jays (Keiper, 1969) to ARB (with the caveat of rearing method confounds). Typically, the opposite is reported for wild-caught mammals, believed to be protected from ARB by their natural, complex upbringing (Mason, 2006a).

627 Captivity can very quickly alter the behaviour of wild-caught birds. Butler et al. (2006) found time in captivity predicted behavioural responses of wild-caught chaffinches, Fringilla coelebs, during a foraging task, with chaffinches held the longest least likely to forage despite having lost the most weight. Furthermore, wild-caught parrots have a greater stress response to an acute stressor than parent-reared and captive-bred birds (Cabezas et al., 632 2013), and are those at highest risk of FDB (Schmid et al., 2006). This latter finding is 633 especially important, as unlike the starlings and blue jays, the origin and ARB-risk

634 relationship is not confounded by rearing technique, i.e. there are parent-reared captive-bred 635 parrots for comparison. Perhaps therefore for some birds, in contrast to wild-caught mammals, the seemingly protective nature of a wild upbringing is outweighed by the acts of removal from the wild and introduction into captivity (with confinement being especially acute 638 for an animal that usually inhabits a significant three-dimensional space). So much so, that 639 behavioural indicators of compromised welfare, including ARB and other behavioural 640 changes, quickly emerge.

641 Studies on internal causal triggers for ARB (principally in laying hens) implicate the roles of 642 neurotransmitters, especially DA (e.g. Kjaer et al., 2004), sex hormones (Hughes, 1973), 643 and dietary deficiencies (e.g. van Krimpen et al., 2007) on FP and other ARBs (e.g.

644 Sandilands et al., 2006). Elevated DA activity is fairly clearly related to increased ARBs, but 645 the relationship is less convincingly established between 5-HT and ARBs. Further 
646 examination of the variation in neurotransmitter-ARB relationships across life-stages (e.g.

647 Kops et al., 2017) is another potentially fruitful area for future studies. The relationship

648 between FP and sex hormones might be explained by changing nutritional needs of laying

649 hens - potentially in female parrots with FDB too - due to the cost of egg production during

650 lay. Energetic requirements increase at this time, and increased pecking may indicate

651 increased feeding motivation, or hunger for nutrients which feathers may provide (Jensen et

652 al., 2005). This could explain why FP is more commonly reported in laying strains of chicken,

653 with their higher levels of egg production, than it is in broiler breeders.

654 CNS dysfunction is an important cause of ARB in other species (reviewed by: Garner, 2006),

655 but it is not yet well-understood in birds. ARBs are reportedly extremely commonplace in

656 some laboratory birds (up to $84.7 \%$ of active time in orange-winged Amazon parrots: Garner

657 et al., 2006), with some evidence for CNS dysfunction (Garner et al., 2003b). Since

658 laboratory-held birds are commonly used in behavioural research (Bateson and Feenders,

659 2010), a prevalence of CNS dysfunction and ARB would undermine the scientific validity of

660 these models of 'normal' function, a matter of significant scientific concern (Garner et al.,

$6612003 b)$.

662 The environment can trigger ARB, though it is unclear how ARB is caused in most cases.

663 Discrete, potentially aversive events such as moving cage (e.g. Feenders and Bateson,

664 2012) or removal of a preferred environment (e.g. Blokhuis and Arkes, 1984) can almost

665 immediately trigger ARB, as can long-term housing in impoverished conditions (e.g. Meehan

666 et al., 2004), and frustration of highly motivated behaviours (e.g. Riber and Mench, 2008). In

667 order to efficiently address ARB, it is essential to first know how environmental conditions

668 have caused the ARB. For instance, we might unnecessarily dismiss an environmental

669 change or enrichment's ability to improve welfare in birds in which irreversible CNS

670 dysfunction has already developed (reviewed by: Mason and Latham, 2004). Establishing

671 causation is therefore fundamental in effectively improving welfare. 
672 Species' evolutionary history can result in mismatches between how the species has

673 evolved to behave and how the captive environment permits individuals to behave, resulting

674 in ARB. Broiler chickens have been artificially selected for rapid weight gain driven by high

675 feeding motivation, indeed, if permitted they eat far beyond what they require for energetic

676 homeostasis (Richards et al., 2010). Broiler breeders are feed-restricted for health reasons

677 (Richards et al., 2010), but with their high feeding motivation show signs of chronic hunger

678 (Mench, 2002), triggering ARBs (e.g. FP: Morrissey et al., 2014a; oral ARBs: Sandilands et

679 al. 2006; Nielsen et al., 2011). Likewise, wild parrots invest heavily in feeding and foraging

680 (Snyder et al., 1987) and their captive counterparts are likely to be similarly motivated. It is

681 perhaps unsurprising that naturally effortful foraging modes emerged as a risk-factor for FDB

682 in parrots (McDonald Kinkaid, 2015), making it clear that for some, foraging behavioural

683 needs are hard to facilitate in captivity. Thus, these evolutionary history mismatches, be it

684 through natural or artificial selection, are influential in ARB and if understood can inform how

685 best to improve welfare. To illustrate, tailoring enrichments to facilitate species-specific

686 foraging modes that are known risk-factors for FDB may help protect against FDB

687 development.

688 Flight, in species capable of flight, is one of the most constrained natural behaviours in 689 captive birds, with restricted flight associated with ARB, as detailed in Section 2.2.4.1 (e.g.

690 Schmid et al., 2006; Mellor, 2014). Whether negative welfare effects of flight restriction have

691 exact parallels with spatial restrictions in mammals, or if there is something special about

692 flight per se which when restricted in captivity compromises welfare, is unclear. To better

693 understand this, future studies could make good use of PCMs to ask whether heavily flight-

694 dependent species are at increased risk of poor captive welfare compared with those that fly 695 less or not at all.

696 There is evidence for heritability in FP in laying hens and, perhaps, FDB in parrots (e.g.

697 Kjaer et al., 2001; Garner et al., 2006). Based on this, it may seem logical to selectively 
breed against ARB, however, this may be costly. To start, other traits could be inadvertently selected for when selecting against ARB (for example, FP may have been accidently selected for whilst breeding for improved egg-production: Nicol, 2015). In divergent lines of mink based on ARB, the low ARB line were more fearful (Hansen and Jeppesen, 2006; Svendsen et al., 2007). Here, selection against ARB may have resulted in selection for apathy, another indication of poor welfare in itself (Fureix and Meagher, 2015). Therefore, purposefully selecting against ARB based on ARB alone is unwise. Early molecular work on genes associated with FP (e.g. Flisikowski et al., 2009; Biscarini et al., 2010; Brunberg et al., 2011), should now be developed further. Ideally future studies should examine other species (e.g. FDB and parrots) and incorporate evidence from causation studies, e.g. examining relationships between ARB and DA and 5-HT expression.

Lastly, we proposed two cautious suggestions of where ARBs may provide function to a bird by facilitating coping: FP and subsequent feather-eating in laying hens (e.g. van Krimpen et al., 2009), and FDB performance associated with disease-related pain (Burgos-Rodríguez, 2010). However, there is also some evidence of instances where ARB may result from a dysfunctional CNS (Garner et al., 2003a; Garner et al., 2003b), and is therefore unlikely to be functional. As implicit in this aetiology of ARB are negative welfare effects of impoverished living conditions (e.g. Hediger, 1950), we need to better understand how a bird's environment affects CNS development. complex aetiologies. Any approach taken to effectively understand and address them, therefore, needs to reflect this. For example, consider FP in laying hens. In severe FP development, the behaviour becomes more prevalent and frequent with age, particularly around the onset of lay, with proactive individuals especially predisposed to FP. Chicks'

722 rearing conditions, such as 'learning' to eat loose feathers, also affect severe FP propensity 723 in later life. In terms of causation, manipulations of neurotransmitters and sex hormones 
demonstrate the internal causal roles they have on FP, while dietary deficiencies and hunger

725 are also important triggers. Considering the evolutionary history of FP, early artificial selection for increased egg-production may have inadvertently also selected for FP, and there are indications that FP may be heritable and under some degree of genetic influence. The function of severe FP, especially if birds consume the feathers they peck, may be to allow the hen to manage a nutritional need not provided by the diet. At present, severe FP is often managed commercially by routine beak-trimming (though it is banned or strictly controlled in some countries: van Horne and Achterbosch, 2008). However, beak-trimming is painful and addresses only the immediate outcome of the behaviour. The alternative approach, as evidenced in the review, is a comprehensive and multi-faceted study of the ARB. For instance: how does a rearing and adult environment with plentiful foraging opportunities interact with chicks being brooded to mitigate severe FP development? Can we select for personality or production traits, such as low mortality rate (see: Nordquist et al., 2011), that interact with these improved conditions in order to reduce FP? It is surely more effective and ethical to comprehensively consider ARB from every perspective, to understand and resolve the problem coherently rather than just addressing the immediate outcome. One important caveat in our above example is our use of evidence from research on severe FP and overall FP (i.e. severe and gentle FP is pooled). Unfortunately FP form is not always specified in scientific papers, though they are very likely distinct behaviours with differing welfare outcomes. We would therefore strongly encourage researchers to

744 discriminate between the two forms of FP wherever possible.

745 To conclude, a diverse range of ARBs are performed by birds. Thousands of avian species are held in different captive settings, as pets, in zoos, as research animals, and extensively in food production, so the scale of ARB and the associated poor welfare is potentially huge.

748 Employing Tinbergen's approach in investigating ARB highlights extensive gaps in our 749 current knowledge. Key areas now requiring attention are: how ARB develops and changes 750 over the course of an individual's lifetime; precisely how the environment causes ARB; a 

comprehensive investigation on a wide range of taxa to better understand evolutionary

752 factors; and, lastly, directed studies to determine whether or not specific ARBs provide 753 function to the performer. Finally, Tinbergen's approach emphasises the complex, multi754 factorial nature of ARB and, importantly, indicates how best to address them.

\section{Conflicts of interest}

756 None.

\section{Acknowledgements}

758 An earlier version of this review formed part of EM's MSc, during which she was kindly part-

759 funded by a Universities Federation for Animal Welfare Small Project and Travel Award

760 (grant number: 62-13/14). We wish to thank Andrea Polanco, Georgia Mason, and three

761 anonymous reviewers for their helpful thoughts and suggestions on previous drafts of this

762 paper, whose comments much improved it.

763

764

765

766

767

768

769

770 
771 References

772 Ambrosen, T., Petersen, V., 1997. The influence of protein level in the diet on cannibalism

773 and quality of plumage of layers. Poultry Sci. 76, 559-563.

774 Appleby, M.C., Hughes, B.O., Elson, H.A., 1992. Poultry production systems. Behaviour, 775 management and welfare. CAB international.

776 Bashaw, M.J., Tarou, L.R., Maki, T.S., Maple, T.L., 2001. A survey assessment of variables

777 related to stereotypy in captive giraffe and okapi. Appl. Anim. Behav. Sci. 73, 235-247.

778 Bateson, M., Feenders, G., 2010. The use of passerine bird species in laboratory research:

779 implications of basic biology for husbandry and welfare. ILAR J. 51, 394-408.

780 Bateson, P., Laland, K.N., 2013. Tinbergen's four questions: an appreciation and an update.

781 Trends Ecol. Evol. 28, 712-718.

782 Benhajali, H., Ezzaouia, M., Lunel, C., Charfi, F., Hausberger, M., 2014. Stereotypic

783 behaviours and mating success in domestic mares. Appl. Anim. Behav. Sci. 153, 36-42.

784 Bessei, W., 1984. Untersuchungen zur heritabilität des Federpickverhaltens bei

785 Junghennen. I. Mitteilung. Arch. Geflügelk 48, 224-231.

786 Bestman, M., Koene, P., Wagenaar, J.-P., 2009. Influence of farm factors on the occurrence

787 of feather pecking in organic reared hens and their predictability for feather pecking in the 788 laying period. Appl. Anim. Behav. Sci. 121, 120-125.

789 Biscarini, F., Bovenhuis, H., van der Poel, J., Rodenburg, T.B., Jungerius, A.P., van

790 Arendonk, J.A.M., 2010. Across-Line SNP Association Study for Direct and Associative

791 Effects on Feather Damage in Laying Hens. Behav. Genet. 40, 715-727. 
792 Blokhuis, H., van der Haar, J., 1992. Effects of pecking incentives during rearing on feather 793 pecking of laying hens. Brit. Poultry Sci. 33, 17-24.

794 Blokhuis, H.J., Arkes, J.G., 1984. Some observations on the development of feather-pecking 795 in poultry. Appl. Anim. Behav. Sci. 12, 145-157.

796 Blokhuis, H.J., Beutler, A., 1992. Feather pecking damage and tonic immobility response in 797 two lines of White Leghorn hens. J. Anim. Sci. 70, 170.

798 Blokhuis, H.J., van der Haar, J.W., 1989. Effects of floor type during rearing and of beak 799 trimming on ground pecking and feather pecking in laying hens. Appl. Anim. Behav. Sci. 22, $800 \quad 359-369$.

801 Blumstein, D.T., Fernández-Juricic, E., 2010. The Evolution of Behavior and Comparative 802 Studies, in: Blumstein, D.T., Fernández-Juricic, E. (Eds.), A Primer of Conservation 803 Behavior, Sinauer Assocites, Inc. Publishers, Sunderland, Massachusetts, pp. 31-41.

804 Bolhuis, J.E., Ellen, E.D., Van Reenen, C.G., De Groot, J., Napel, J.T., Koopmanschap, 805 R.E., De Vries Reilingh, G., Uitdehaag, K.A., Kemp, B., Rodenburg, T.B., 2009. Effects of 806 genetic group selection against mortality on behavior and peripheral serotonin in domestic 807 laying hens with trimmed and intact beaks. Physiol. Behav. 97, 470-475.

808 Brilot, B.O., Asher, L., Feenders, G., Bateson, M., 2009. Quantification of abnormal repetitive 809 behaviour in captive European starlings (Sturnus vulgaris). Behav. Process. 82, 256-264.

810 Brunberg, E., Jensen, P., Isaksson, A., Keeling, L., 2011. Feather pecking behavior in laying 811 hens: Hypothalamic gene expression in birds performing and receiving pecks. Poult. Sci. 90, $812 \quad 1145-1152$. 
813 Brunberg, E.I., Rodenburg, T.B., Rydhmer, L., Kjaer, J.B., Jensen, P., Keeling, L.J., 2016.

814 Omnivores Going Astray: A Review and New Synthesis of Abnormal Behavior in Pigs and 815 Laying Hens. Front. Vet. Sci. 3, 57.

816 Buitenhuis, A., Rodenburg, T., Siwek, M., Cornelissen, S., Nieuwland, M., Crooijmans, R., 817 Groenen, M., Koene, P., Bovenhuis, H., van der Poel, J., 2003a. Identification of quantitative 818 trait loci for receiving pecks in young and adult laying hens. Poultry Sci. 82, 1661-1667.

819 Buitenhuis, A., Rodenburg, T., van Hierden, Y., Siwek, M., Cornelissen, S., Nieuwland, M., 820 Crooijmans, R., Groenen, M., Koene, P., Korte, S., 2003b. Mapping quantitative trait loci 821 affecting feather pecking behavior and stress response in laying hens. Poultry Sci. 82, 12158221222

823 Buitenhuis, A.J., Kjaer, J.B., Labouriau, R., Juul-Madsen, H.R., 2006. Altered circulating 824 levels of serotonin and immunological changes in laying hens divergently selected for 825 feather pecking behavior. Poultry Sci. 85, 1722-1728.

826 Burgos-Rodríguez, A.G., 2010. Avian Renal System: Clinical Implications. Vet. Clin. N. Am827 Exotic 13, 393-411.

828 Burman, O.H.P., Parker, R.M.A., Paul, E.S., Mendl, M., 2008. Sensitivity to reward loss as 829 an indicator of animal emotion and welfare. Biol. Lett. 4, 330-333.

830 Butler, D., Davis, C., 2010. Effects of plastic bits on the condition and behaviour of captive831 reared pheasants. Vet. Rec. 166, 398-401.

832 Butler, S., Whittingham, M., Quinn, J., Cresswell, W., 2006. Time in captivity, individual 833 differences and foraging behaviour in wild-caught chaffinches. Behaviour 143, 535-548. 
834 Cabezas, S., Carrete, M., Tella, J.L., Marchant, T.A., Bortolotti, G.R., 2013. Differences in

835 acute stress responses between wild-caught and captive-bred birds: a physiological

836 mechanism contributing to current avian invasions? Biol. Invasions 15, 521-527.

837 Carlstead, K., 1998. Determining the causes of stereotypic behaviours in zoo carnivores:

838 towards developing appropriate enrichment., in: Shepherdson, D.J., Mellen, J., Hutchines,

839 M. (Eds.), Second Nature: Environmental Enrichment for Captive Mammals., Smithsonian

840 Institution Press, Washington DC, pp. 172-183.

841 Castagna, C., Ball, G.F., Balthazart, J., 1997. Effects of Dopamine Agonists on Appetitive 842 and Consummatory Male Sexual Behavior in Japanese Quail. Pharmacol. Biochem. Be. 58, $843403-414$.

844 Clubb, R., Mason, G., 2003. Animal Welfare: Captivity effects on wide-ranging carnivores.

$845 \quad$ Nature 425, 473-474.

846 Clubb, R., Mason, G.J., 2007. Natural behavioural biology as a risk factor in carnivore 847 welfare: How analysing species differences could help zoos improve enclosures. Appl. Anim. 848 Behav. Sci. 102, 303-328.

849 Clyde, V.L., Patton, S., 1996. Diagnosis, treatment, and control of common parasites in 850 companion and aviary birds, Seminars in Avian and Exotic Pet Medicine, Elsevier, pp. 75-84.

851 Conde, D.A., Flesness, N., Colchero, F., Jones, O.R., Scheuerlein, A., 2011. An Emerging 852 Role of Zoos to Conserve Biodiversity. Science 331, 1390-1391.

853 Coppens, C.M., de Boer, S.F., Koolhaas, J.M., 2010. Coping styles and behavioural 854 flexibility: towards underlying mechanisms. Philos. T. Roy. Soc. B 365, 4021-4028.

855 Coulon, M., Henry, L., Perret, A., Cousillas, H., Hausberger, M., George, I., 2014. Assessing 856 Video Presentations as Environmental Enrichment for Laboratory Birds. PLos ONE 9. 
857 Cussen, V.A., Mench, J.A., 2015. The relationship between personality dimensions and

858 resiliency to environmental stress in orange-winged amazon parrots (Amazona amazonica),

859 as indicated by the development of abnormal behaviors. PLoS One 10, e0126170.

860 Cuthbertson, G.J., 1980. Genetic variation in feather-pecking behaviour. Brit. Poultry Sci. 21, $861 \quad 447-450$.

862 Dalton, H., Wood, B., Torrey, S., 2013. Injurious pecking in domestic turkeys: development, 863 causes, and potential solutions. World's Poultry Sci. J. 69, 865-876.

864 Degen, A.A., Kam, M., Rosenstrauch, A., 1989. Time-activity budget of ostriches (Struthio 865 camelus) offered concentrate feed and maintained in outdoor pens. Appl. Anim. Behav. Sci. $866 \quad 22,347-358$.

867 D'Eath, R.B., Tolkamp, B.J., Kyriazakis, I., Lawrence, A.B., 2009. 'Freedom from hunger' 868 and preventing obesity: the animal welfare implications of reducing food quantity or quality. 869 Anim. Behav. 77, 275-288.

870 de Jong, I.C., Guémené, D., 2011. Major welfare issues in broiler breeders. World’s Poultry 871 Sci. J. 67, 73-82.

872 de Jong, I.C., Voorst, S.V., Ehlhardt, D.A., Blokhuis, H.J., 2002. Effects of restricted feeding 873 on physiological stress parameters in growing broiler breeders. Brit. Poultry Sci. 43, 157874168.

875 Díez-León, M., Bowman, J., Bursian, S., Filion, H., Galicia, D., Kanefsky, J., Napolitano, A., 876 Palme, R., Schulte-Hostedde, A., Scribner, K., 2013. Environmentally enriched male mink 877 gain more copulations than stereotypic, barren-reared competitors. PLoS One 8, e80494. 
878 Dixon, L.M., Duncan, I.J.H., Mason, G., 2008. What's in a peck? Using fixed action pattern

879 morphology to identify the motivational basis of abnormal feather-pecking behaviour. Anim.

880 Behav. 76, 1035-1042.

881 Doneley, R.J., 2009. Bacterial and parasitic diseases of parrots. Vet. Clin. N. Am.-Exotic 12, $882 \quad 417-432$.

883 Duncan, I.J.H., Wood-Gush, D.G.M., 1972. Thwarting of feeding behaviour in the domestic 884 fowl. Anim. Behav. 20, 444-451.

885 Edgar, J., Held, S., Jones, C., Troisi, C., 2016. Influences of Maternal Care on Chicken 886 Welfare. Animals 6, 2.

887 Eilam, D., Izhar, R., Mort, J., 2011. Threat detection: Behavioral practices in animals and 888 humans. Neurosci. Biobehav. R. 35, 999-1006.

889 El-Lethey, H., Aerni, V., Jungi, T., Wechsler, B., 2000. Stress and feather pecking in laying 890 hens in relation to housing conditions. Brit. Poultry Sci. 41, 22-28.

891 Elwinger, K., Tufvesson, M., Lagerkvist, G., Tauson, R., 2008. Feeding layers of different 892 genotypes in organic feed environments. Brit. Poultry Sci. 49, 654-665.

893 FAO, 2014. FAOSTAT: Number of layer hens and broilers produced worldwide in 2014.

894 http://www.fao.org/faostat/en/\#data/QL accessed 16/08/2017

895 Faure, J., Bessei, W., Jones, R., 2003. Direct Selection for Improvement of Animal Well896 being. Poultry Genetics, Breeding, and Biotechnology, pp. 221-245.

897 Feenders, G., Bateson, M., 2011. Hand-rearing reduces fear of humans in European 898 starlings, Sturnus vulgaris. PLoS One 6, e17466. 
899 Feenders, G., Bateson, M., 2012. The development of stereotypic behavior in caged

900 European starlings, Sturnus vulgaris. Dev. Psychobiol. 54, 773-784.

901 Feenders, G., Bateson, M., 2013. Hand rearing affects emotional responses but not basic 902 cognitive performance in European starlings. Anim. Behav. 86, 127-138.

903 Flisikowski, K., Schwarzenbacher, H., Wysocki, M., Weigend, S., Preisinger, R., Kjaer, J.B.,

904 Fries, R., 2009. Variation in neighbouring genes of the dopaminergic and serotonergic

905 systems affects feather pecking behaviour of laying hens. Anim. Genet. 40, 192-199.

906 Fureix, C., Meagher, R.K., 2015. What can inactivity (in its various forms) reveal about 907 affective states in non-human animals? A review. Appl. Anim. Behav. Sci. 171, 8-24.

908 Garner, J.P., 2006. Perseveration and Stereotypy - Systems-level Insights from Clinical 909 Psychology, in: Mason, G., Rushen, J. (Eds.), Stereotypic Animal Behaviour: Fundamentals 910 and Applications to Welfare, CABI, Oxfordshire, UK, pp. 121-152.

911 Garner, J.P., Mason, G.J., 2002. Evidence for a relationship between cage stereotypies and behavioural disinhibition in laboratory rodents. Behav. Brain Res. 136, 83-92.

913 Garner, J.P., Mason, G.J., Smith, R., 2003a. Stereotypic route-tracing in experimentally

914 caged songbirds correlates with general behavioural disinhibition. Anim. Behav. 66, 711-727.

915 Garner, J.P., Meehan, C.L., Famula, T.R., Mench, J.A., 2006. Genetic, environmental, and 916 neighbor effects on the severity of stereotypies and feather picking in Orange-winged 917 Amazon parrots (Amazona amazonica): An epidemiological study. Appl. Anim. Behav. Sci. $91896,153-168$.

919 Garner, J.P., Meehan, C.L., Mench, J.A., 2003b. Stereotypies in caged parrots, 920 schizophrenia and autism: evidence for a common mechanism. Behav. Brain Res. 145, 125921134. 
922 Gaskins, L.A., Bergman, L. , 2011. Surveys of avian practitioners and pet owners regarding

923 common behavior problems in psittacine birds. J. Avian Med. Surg. 25, 111-118.

924 Gentle, M.J., Waddington, D., Hunter, L.N., Jones, R.B., 1990. Behavioural evidence for 925 persistent pain following partial beak amputation in chickens. Appl. Anim. Behav. Sci. 27, $926 \quad 149-157$.

927 Gilani, A.-M., Knowles, T.G., Nicol, C.J., 2013. The effect of rearing environment on feather 928 pecking in young and adult laying hens. Appl. Anim. Behav. Sci. 148, 54-63.

929 Glatz, P., 2000. Effect of declawing on behavior of farmed emus. Asian Austral J. Anim. 14, $930 \quad 288-296$.

931 Glatz, P.C., Murphy, L., Reston, A., 1992. Analgesic therapy of beak-trimmed chickens.

932 Aust. Vet. J. 69, 18-18.

933 Gustafson, L.A., Cheng, H.-W., Garner, J.P., Pajor, E.A., Mench, J.A., 2007. Effects of bill934 trimming Muscovy ducks on behavior, body weight gain, and bill morphopathology. Appl. 935 Anim. Behav. Sci. 103, 59-74.

936 Hansen, S.W., Jeppesen, L.L., 2006. Temperament, stereotypies and anticipatory behaviour 937 as measures of welfare in mink. Appl. Anim. Behav. Sci. 99, 172-182.

938 Harlander-Matauschek, A., Baes, C., Bessei, W., 2006a. The demand of laying hens for 939 feathers and wood shavings. Appl. Anim. Behav. Sci. 101, 102-110.

940 Harlander-Matauschek, A., Piepho, H., Bessei, W., 2006b. The effect of feather eating on 941 feed passage in laying hens. Poultry Sci. 85, 21-25.

942 Harms, R., Russell, G., 1996. A re-evaluation of the methionine requirement of the 943 commercial layer. J. Appl. Anim. Res. 9, 141-151. 
944 Harvey, N.C., Farabaugh, S.M., Druker, B.B., 2002. Effects of Early Rearing Experience on

945 Adult Behavior and Nesting in Captive Hawaiian Crows (Corvus hawaiiensis). Zoo Biol. 21, $946 \quad 59-75$.

947 Hediger, H., 1950. Wild Animals in Captivity. Butterworths, London.

948 Hesterman, H., Gregroy, N.G., Boardman, W.S.J., 2001. Deflighting procedures and their 949 welfare implications in captive birds. Anim. Welf. 10, 405-419.

950 Hetland, H., Choct, M., Svihus, B., 2004. Role of insoluble non-starch polysaccharides in 951 poultry nutrition. World's Poultry Sci. J. 60, 415-422.

952 Hocking, P.M., Maxwell, M.H., Mitchell, M.A., 1993. Welfare assessment of broiler breeder 953 and layer females subjected to food restriction and limited access to water during rearing.

954 Brit. Poultry Sci. 34, 443-458.

955 Huber-Eicher, B., Sebö, F., 2001. The prevalence of feather pecking and development in 956 commercial flocks of laying hens. Appl. Anim. Behav. Sci. 74, 223-231.

957 Hughes, B., 1973. The effect of implanted gonadal hormones on feather pecking and 958 cannibalism in pullets. Brit. Poultry Sci. 14, 341-348.

959 Hughes, B., 1985. Feather loss-how does it occur, Proceedings of the 2nd European 960 Poultry Welfare Symposium, Edinburgh, pp. 178-188.

961 Iglauer, F., Rasim, R., 1993. Treatment of psychogenic leather picking in psittacine birds 962 with a dopamine antagonist. J. Small Anim. Pract. 34, 564-566.

963 Ijichi, C.L., Collins, L.M., Elwood, R.W., 2013. Evidence for the role of personality in 964 stereotypy predisposition. Anim. Behav. 85, 1145-1151. 
965 Jacobs, H., Smith, N., Smith, P., Smyth, L., Yew, P., Saibaba, P., Hau, J., 1995. Zebra finch

966 behaviour and effect of modest enrichment of standard cages. Anim. Welf. 4, 3-9.

967 Jaensch, S., 2000. Diagnosis of avian hepatic disease, Seminars in Avian and Exotic Pet 968 Medicine, Elsevier, pp. 126-135.

969 Jensen, P., Keeling, L., Schütz, K., Andersson, L., Mormède, P., Brändström, H., Forkman,

970 B., Kerje, S., Fredriksson, R., Ohlsson, C., Larsson, S., Mallmin, H., Kindmark, A., 2005.

971 Feather pecking in chickens is genetically related to behavioural and developmental traits.

972 Physiol. Behav. 86, 52-60.

973 Jones, T.A., Waitt, C.D., Dawkins, M.S., 2009. Water off a duck's back: showers and troughs

974 match ponds for improving duck welfare. Appl. Anim. Behav. Sci. 116, 52-57.

975 Keeling, L., Andersson, L., Schütz, K.E., Kerje, S., Fredriksson, R., Carlborg, Ö., Cornwallis,

976 C.K., Pizzari, T., Jensen, P., 2004. Chicken genomics: feather-pecking and victim

977 pigmentation. Nature 431, 645-646.

978 Keiper, R.R., 1969. Causal factors of stereotypies in caged birds. Anim. Behav. 17, 114-119.

979 Keiper, R.R., 1970. Studies of stereotypy function in the canary (Serinus canarius). Anim.

980 Behav. 18, 353-357.

981 Kjaer, J., Bessei, W., 2013. The interrelationships of nutrition and feather pecking in the 982 domestic fowl. Arch Geflügelk 77, 1-9.

983 Kjaer, J., Sørensen, P., 1997. Feather pecking behaviour in White Leghorns, a genetic 984 study. Brit. Poultry Sci. 38, 333-341.

985 Kjaer, J.B., 2009. Feather Pecking in Domestic Fowl is Genetically Related to Locomotor 986 Activity Levels: Implications for a Hyperactivity Disorder Model of Feather Pecking. Behav. 987 Genet. 39, 564-570. 
Kjaer, J.B., Hjarvard, B.M., Jensen, K.H., Hansen-Møller, J., Naesbye Larsen, O., 2004.

989 Effects of haloperidol, a dopamine D2 receptor antagonist, on feather pecking behaviour in 990 laying hens. Appl. Anim. Behav. Sci. 86, 77-91.

991 Kjaer, J.B., Sørensen, P., Su, G., 2001. Divergent selection on feather pecking behaviour in 992 laying hens (Gallus gallus domesticus). Appl. Anim. Behav. Sci. 71, 229-239.

Kjaer, J.B., Würbel, H., Schrader, L., 2015. Perseveration in a guessing task by laying hens selected for high or low levels of feather pecking does not support classification of feather pecking as a stereotypy. Appl. Anim. Behav. Sci. 168, 56-60.

Klopfer, P.H., Hailman, J.P., 1972. Function and Evolution of Behavior. Addison-Wesley, 997 United States.

998

Koolhaas, J., Korte, S., De Boer, S., van der Vegt, B., van Reenen, C., Hopster, H., de Jong, 999 I., Ruis, M., Blokhuis, H., 1999. Coping styles in animals: current status in behavior and stress-physiology. Neurosci. Biobehav. R. 23, 925-935.

Kops, M.S., Kjaer, J.B., Güntürkün, O., Westphal, K.G.C., Korte-Bouws, G.A.H., Olivier, B., 1002 Korte, S.M., Bolhuis, J.E., 2017. Brain monoamine levels and behaviour of young and adult 1003 chickens genetically selected on feather pecking. Behav. Brain Res. 327, 11-20.

1004 Koštál, L., Savory, C., 1995. Serotonergic mechanisms in control of stereotypies in fowls. 1005 Appl. Anim. Behav. Sci. 44, 267.

1006 Kroshko, J., Clubb, R., Harper, L., Mellor, E., Moehrenschlage, A., Mason, G., 2016.

1007 Stereotypic route-tracing in captive Carnivora is predicted by species-typical home range 1008 sizes and hunting styles. Anim. Behav. 117, 197-209.

1009 Labouriau, R., Kjaer, J., Abreu, G., Hedegaard, J., Buitenhuis, A., 2009. Analysis of severe 1010 feather pecking behavior in a high feather pecking selection line. Poultry Sci. 88, 2052-2062. 
1011 Lambton, S.L., Knowles, T.G., Yorke, C., Nicol, C.J., 2010. The risk factors affecting the 1012 development of gentle and severe feather pecking in loose housed laying hens. Appl. Anim. 1013 Behav. Sci. 123, 32-42.

1014 Lang, M., Krátký, J., Shaver, J.H., Jerotijević, D., Xygalatas, D., 2015. Effects of anxiety on 1015 spontaneous ritualized behavior. Curr. Biol. 25, 1892-1897.

1016 Langen, M., Kas, M.J.H., Staal, W.G., van Engeland, H., Durston, S., 2011. The 1017 neurobiology of repetitive behavior: Of mice.... Neurosci. Biobehav. R. 35, 345-355.

1018 Laurence, A., Houdelier, C., Calandreau, L., Arnould, C., Favreau-Peigné, A., Leterrier, C., 1019 Boissy, A., Lumineau, S., 2015. Environmental enrichment reduces behavioural alterations 1020 induced by chronic stress in Japanese quail. Animal 9, 331-338.

1021 Leipoldt, A.L., 1992. Gedrag van pekingeenden met variatie in drinkwatersysteem en 1022 bodembedekking. Praktijkonderzoek voor de Pluimveehouderij, PP-uitgave no. 03.

1023 Leitner, S., Catchpole, C.K., 2007. Song and brain development in canaries raised under 1024 different conditions of acoustic and social isolation over two years. Dev. Neurobiol. 67, 147810251487.

1026 Lewis, M.H., Presti, M.F., Lewis, J.B., Turner, C.A., 2006. The Neurobiology of Stereotypy I: 1027 Environmental Complexity, in: Mason, G., Rushen, J. (Eds.), Stereotypic Animal Behaviour: 1028 Fundamentals and Applications to Welfare, CABI Oxfordshire, UK, pp. 190-226.

1029 Lumeij, J.T., Hommers, C.J., 2008. Foraging 'enrichment' as treatment for pterotillomania. 1030 Appl. Anim. Behav. Sci. 111, 85-94.

1031 Machlis, L.E., 1980. Apomorphine: Effects on the timing and sequencing of pecking behavior 1032 in chicks. Pharmacol. Biochem. Be. 13, 331-336. 
1033 Marston, L.C., Bennett, P.C., Coleman, G.J., 2004. What Happens to Shelter Dogs? An

1034 Analysis of Data for 1 Year From Three Australian Shelters. J. Appl. Anim. Welf. Sci. 7, 27-

$1035 \quad 47$

1036 Martrenchar, A., Huonnic, D., Cotte, J., 2001. Influence of environmental enrichment on

1037 injurious pecking and perching behaviour in young turkeys. Brit. Poultry Sci. 42, 161-170.

1038 Mason, G., 2006a. Box 7.1 Are Wild-Born Animals 'Protected' from Stereotypy When Placed 1039 in Captivity?, in: Mason, G., Rushen, J. (Eds.), Stereotypic Animal Behaviour. Fundamentals 1040 and Applications to Welfare, CABI, Oxfordshire, UK, p. 196.

1041 Mason, G., 2006b. Stereotypic Behaviour in Captive Animals: Fundamentals and

1042 Implications for Welfare and Beyond, in: Mason, G., Rushen, J. (Eds.), Stereotypic Animal

1043 Behaviour: Fundamentals and Applications to Welfare, CAB International, Wallingford, pp.

$1044 \quad 325-367$.

1045 Mason, G.J., 1991a. Stereotypies and suffering. Behav. Process. 25, 103-115.

1046 Mason, G.J., 1991b. Stereotypies: a critical review. Anim. Behav. 41, 1015-1037.

1047 Mason, G.J., 2010. Species differences in responses to captivity: stress, welfare and the 1048 comparative method. Trends Ecol. Evol. 25, 713-721.

1049 Mason, G.J., Latham, N.R., 2004. Can't stop, won't stop: is stereotypy a reliable animal 1050 welfare indicator? Anim. Welf. 13, 57-69.

1051 Mayr, E., 1961. Cause and effect in biology. Science 134, 1501-1506.

1052 McAdie, T.M., Keeling, L., 2000. Effect of manipulating feathers of laying hens on the 1053 incidence of feather pecking and cannibalism. Appl. Anim. Behav. Sci. 68, 215-229. 
McBride, S.D., Long, L., 2001. Management of horses showing stereotypic behaviour, owner perception and the implications for welfare. Vet. Rec. 148, 799-802.

McDonald Kinkaid, H.Y., 2015. Species-Level Determinants of Stereotypic Behaviour, Reproductive Success, and Lifespan in Captive Parrots (Psittaciformes), Animal and Poultry Science, University of Guelph, Canada.

McKeegan, D.E., Savory, C., 1999. Feather eating in layer pullets and its possible role in the 1060 aetiology of feather pecking damage. Appl. Anim. Behav. Sci. 65, 73-85.

1061

Meehan, C.L., Garner, J.P., Mench, J.A., 2003a. Isosexual pair housing improves the 1062 welfare of young Amazon parrots. Appl. Anim. Behav. Sci. 81, 73-88.

Meehan, C.L., Garner, J.P., Mench, J.A., 2004. Environmental enrichment and development 1064 of cage stereotypy in Orange-winged Amazon parrots (Amazona amazonica). Dev.

1065 Psychobiol. 44, 209-218.

Meehan, C.L., Millam, J.R., Mench, J.A., 2003b. Foraging opportunity and increased physical complexity both prevent and reduce psychogenic feather picking by young Amazon parrots. Appl. Anim. Behav. Sci. 80, 71-85.

Mellor, E., 2014. Can we use biological risk factors for stereotypic behaviour in parrots to predict husbandry risk factors? School of Biological Sciences, Plymouth University, 1071 Plymouth, UK.

1072 Mench, J.A., 2002. Broiler breeders: feed restriction and welfare. World's Poultry Sci.J. 58, $1073 \quad 23-29$.

1074 Mertens, P.A., 1997. Pharmacological treatment of feather picking in pet birds. , In: Mills, 1075 D.S., Heath, S.E. (Eds.), Proceedings of the First International Conference on Veterinary 1076 Behavioral Medicine, UFAW, Potters Bar, UK., pp. 209-213. 
Meyer-Holzapfel, M., 1968. Abnormal behaviour in zoo animals, in: Fox, M.W. (Ed.),

1078 Abnormal Behaviour in Animals, Saunders, London, pp. 476-503.

1079

1080

1081

1082

1083

1084

1085

1086

1087

1088

1089

1090

1091

1092

1093

1094

1095

1096

1097

1098

1099

Miller, L.J., 2012. Visitor reaction to pacing behavior: influence on the perception of animal care and interest in supporting zoological institutions. Zoo Biol. 31, 242- 248.

Moon-Fanelli, A.A., Dodman, N.H., O'Sullivan, R.L., 1999. Veterinary models of compulsive self-grooming: parallels with trichotillomania, in: Stein, D.J., Christenson, G.A., Hollander, E. (Eds.), Trichotillomania, American Psychiatric Press, Washington DC, USA, pp. 63-92.

Morris, D., 1964. The response of animals to a restricted environment, Symposium of the Zoological Society., London, pp. 99-120.

Morrissey, K.L.H., Widowski, T., Leeson, S., Sandilands, V., Arnone, A., Torres, J., 2014a.

The effect of dietary alterations during rearing on growth, productivity, and behavior in broiler breeder females. Poultry Sci. 93, 285-295.

Morrissey, K.L.H., Widowski, T., Leeson, S., Sandilands, V., Arnone, A., Torrey, S., 2014b.

The effect of dietary alterations during rearing on feather condition in broiler breeder females. Poultry Sci. 93, 1636-1643.

Müller, D.W., Lackey, L.B., Streich, W.J., Fickel, J., Hatt, J.M., Clauss, M., 2011. Mating system, feeding type and ex situ conservation effort determine life expectancy in captive ruminants. P. R. Soc. B 278, 2076-2080.

Nettle, D., Penke, L., 2010. Personality: bridging the literatures from human psychology and behavioural ecology. Philos. T. Roy. Soc. B. 365, 4043-4050.

Newberry, R.C., Keeling, L.J., Estevez, I., Bilčík, B., 2007. Behaviour when young as a predictor of severe feather pecking in adult laying hens: The redirected foraging hypothesis revisited. Appl. Anim. Behav. Sci. 107, 262-274. 
1100 Nicol, C.J., 2015. Genetics and Domestication, The Behavioural Biology of Chickens, CABI,

1101 Oxfordshire, UK, pp. 1-14.

1102 Nicol, C.J., Lindberg, A.C., Phillips, A.J., Pope, S.J., Wilkins, L.J., Green, L.E., 2001.

1103 Influence of prior exposure to wood shavings on feather pecking, dustbathing and foraging in 1104 adult laying hens. Appl. Anim. Behav. Sci. 73, 141-155.

1105 Nielsen, B.L., Thodberg, K., Malmkvist, J., Steenfeldt, S., 2011. Proportion of insoluble fibre 1106 in the diet affects behaviour and hunger in broiler breeders growing at similar rates. Animal $1107 \quad 5,1247-1258$.

1108 Nordquist, R.E., Heerkens, J.L.T., Rodenburg, T.B., Boks, S., Ellen, E.D., van der Staay, 1109 F.J., 2011. Laying hens selected for low mortality: Behaviour in tests of fearfulness, anxiety 1110 and cognition. Appl. Anim. Behav. Sci. 131, 110-122.

1111 Nordquist, R.E., Zeinstra, E.C., Rodenburg, T.B., van der Staay, F.J., 2013. Effects of 1112 maternal care and selection for low mortality on tyrosine hydroxylase concentrations and cell 1113 soma size in hippocampus and nidopallium caudolaterale in adult laying hen. J. Anim. Sci. $111491,137-146$

1115 Norman, D.A., Shallice, T., 1986. Attention to action: willed and automatic control of 1116 behaviour., in: Davidson, R.J., Schwartz, G.E., Shapiro, D. (Eds.), Consciousness and self1117 regulation: advances in research and theory., Plenum Press, New York, pp. 1-18.

1118 Novak, M., 2003. Self-injurious behavior in rhesus monkeys: New insights into its etiology, 1119 physiology, and treatment. Am. J. Primatol. 59, 3-19.

1120 Ödberg, F., 1978. Abnormal behaviours: stereotypies., In: Garsi, E. (Ed.), Proceedings of the 1121 1st World Congress on Ethology Applied to Zootechnics, Industrias Graficas Espana, 1122 Madrid, pp. 475-480. 
1123 Parmentier, H.K., Rodenburg, T.B., De Vries Reilingh, G., Beerda, B., Kemp, B., 2009. Does

1124 enhancement of specific immune responses predispose laying hens for feather pecking?

1125 Poult. Sci. 88, 536-542.

1126 Patzke, N., Ocklenburg, S., van der Staay, F.J., Güntürkün, O., Manns, M., 2009.

1127 Consequences of different housing conditions on brain morphology in laying hens. J. Chem.

1128 Neuroanat. 37, 141-148.

1129 Peng, S.J.-L., Chang, F.-C., Sheng-Ting, J.I., Fei, A.C.-Y., 2013. Welfare assessment of 1130 flight-restrained captive birds: effects of inhibition of locomotion. Thai J. Vet. Med. 43, 235.

1131 Perré, Y., Wauters, A.-M., Richard-Yris, M.-A., 2002. Influence of mothering on emotional 1132 and social reactivity of domestic pullets. Appl. Anim. Behav. Sci. 75, 133-146.

1133 Polanco, A., 2016. A Tinbergian review of self-injurious behaviors in laboratory rhesus 1134 macaques. Appl. Anim. Behav. Sci. 179, 1-10.

1135 Polverino, G., Manciocco, A., Vitale, A., Alleva, E., 2015. Stereotypic behaviours in 1136 Melopsittacus undulatus: Behavioural consequences of social and spatial limitations. Appl. 1137 Anim. Behav. Sci. 165, 143-155.

1138 Pomerantz, O., Meiri, S., Terkel, J., 2013. Socio-ecological factors correlate with levels of 1139 stereotypic behavior in zoo-housed primates. Behav. Process. 98, 85-91.

1140 Pötzsch, C.J., Lewis, K., Nicol, C.J., Green, L.E., 2001. A cross-sectional study of the 1141 prevalence of vent pecking in laying hens in alternative systems and its associations with 1142 feather pecking, management and disease. Appl. Anim. Behav. Sci. 74, 259-272.

1143 Quentin, M., Bouvarel, I., Picard, M., 2005. Effects of crude protein and lysine contents of 1144 the diet on growth and body composition of slow-growing commercial broilers from 42 to 77 1145 days of age. Anim. Res. 54, 113-122. 
1146 Ramadan, S., von Borell, E., 2008. Role of loose feathers on the development of feather

1147 pecking in laying hens. Brit. Poultry Sci. 49, 250-256.

1148 Ramage, A., Bayles, K., Helm-Estabrooks, N., Cruz, R., 1999. Frequency of perseveration in 1149 normal subjects. Brain Lang. 66, 329-340.

1150 Riedstra B, Groothuis TGG. 2002. Early feather pecking as a form of social exploration: the 1151 effect of group stability on feather pecking and tonic immobility in domestic chicks. Appl.

1152 Anim. Behav. Sci. 77:127-138.

1153 Renema, R.A., Rustad, M.E., Robinson, F.E., 2007. Implications of changes to commercial 1154 broiler and broiler breeder body weight targets over the past 30 years. World's Poultry Sci. J. $115563,457-472$.

1156 Riber, A.B., Mench, J.A., 2008. Effects of feed-and water-based enrichment on activity and 1157 cannibalism in Muscovy ducklings. Appl. Anim. Behav. Sci. 114, 429-440.

1158 Riber, A.B., Wichman, A., Braastad, B.O., Forkman, B., 2007. Effects of broody hens on 1159 perch use, ground pecking, feather pecking and cannibalism in domestic fowl (Gallus gallus 1160 domesticus). Appl. Anim. Behav. Sci. 106, 39-51.

1161 Richards, M., Rosebrough, R., Coon, C., McMurtry, J., 2010. Feed intake regulation for the 1162 female broiler breeder: In theory and in practice. J. Appl. Poultry Res. 19, 182-193.

1163 Rodenburg, T., Bracke, M., Berk, J., Cooper, J., Faure, J., Guemene, D., Guy, G., 1164 Harlander, A., Jones, T., Knierim, U., 2005. Welfare of ducks in European duck husbandry 1165 systems. World's Poultry Sci. J. 61, 633-646.

1166 Rodenburg, T., Buitenhuis, A., Ask, B., Uitdehaag, K., Koene, P., van der Poel, J., 1167 Bovenhuis, H., 2003. Heritability of feather pecking and open-field response of laying hens at 1168 two different ages. Poultry Sci. 82, 861-867. 
1169 Rodenburg, T., van Krimpen, M., de Jong, I., De Haas, E., Kops, M., Riedstra, B., Nordquist,

1170 R., Wagenaar, J., Bestman, M., Nicol, C., 2013. The prevention and control of feather

1171 pecking in laying hens: identifying the underlying principles. World's Poultry Sci. J. 69, 361-

1172374.

1173 Sahakian, B.J., Robbins, T.W., Morgan, M.J., Iversen, S.D., 1975. The effects of

1174 psychomotor stimulants on stereotypy and locomotor activity in socially-deprived and control

1175 rats. Brain Res. 84, 195-205.

1176 Saint-Dizier, H., Leterrier, C., Lévy, F., Richard, S., 2008. Selection for tonic immobility

1177 duration does not affect the response to novelty in quail. Appl. Anim. Behav. Sci. 112, 297-

1178306.

1179 Samson, J., 1996. Behavioral problems of farmed ostriches in Canada. Canadian Vet. J. 37, $1180 \quad 412-414$

1181 Sandilands, V., Tolkamp, B.J., Savory, C.J., Kyriazakis, I., 2006. Behaviour and welfare of 1182 broiler breeders fed qualitatively restricted diets during rearing: Are there viable alternatives 1183 to quantitative restriction? Appl. Anim. Behav. Sci. 96, 53-67.

1184 Savory, C.J., 1995. Feather pecking and cannibalism. World's Poultry Sci. J. 51, 215-219.

1185 Savory, C., 1998. Feather pecking damage in growing bantams is influenced by dietary 1186 tryptophan concentration but not dietary protein source. Brit. Poultry Sci. 39, 17-18.

1187 Savory, C., Mann, J., Macleod, M., 1999. Incidence of pecking damage in growing bantams 1188 in relation to food form, group size, stocking density, dietary tryptophan concentration and 1189 dietary protein source. Brit. Poultry Sci. 40, 579-584. 
1190 Savory, C.J., Maros, K., Rutter, S.M., 1993. Assessment of Hunger in Growing Broiler

1191 Breeders in Relation to a Commercial Restricted Feeding Programme. Anim. Welf. 2, 1311192152.

1193 Schmid, R., Doherr, M.G., Steiger, A., 2006. The influence of the breeding method on the 1194 behaviour of adult African grey parrots (Psittacus erithacus). Appl. Anim. Behav. Sci. 98, $1195 \quad 293-307$.

1196 Sirén, M.J., 1963. A factor preventing cannibalism in cockerels. Life Sci. 2, 120-124.

1197 Snyder, N., Wieley, J., Kepler, C., 1987. The parrots of Luquillo: natural history and 1198 conservation of the Puerto Rican parrot. Western Foundation of Vertebrate Zoology. USA.

Stokes, A.W., 1971. Parental and Courtship Feeding in Red Jungle Fowl. The Auk 88, 21-

1200 29.

1201

Svendsen, P.M., Hansen, B.K., Malmkvist, J., Hansen, S.W., Palme, R., Jeppesen, L.L., 2007. Selection against stereotypic behaviour may have contradictory consequences for the welfare of farm mink (Mustela vison). Appl. Anim. Behav. Sci. 107, 110-119.

Tahamtani, F.M., Brantsæter, M., Nordgreen, J., Sandberg, E., Hansen, T.B., Nødtvedt, A., 1205 Rodenburg, T.B., Moe, R.O., Janczak, A.M., 2016. Effects of litter provision during early rearing and environmental enrichment during the production phase on feather pecking and feather damage in laying hens. Poultry Sci.

1208 Tinbergen, N., 1963. On aims and methods of ethology. Zeitschrift für Tierpsychologie 20, $1209 \quad 410-433$.

1210 Tolkamp, B.J., D'Eath, R.B., 2016. Hunger Associated with Restricted Feeding Systems, in: 1211 Phillips, C.J.C. (Ed.), Nutrition and the Welfare of Farm Animals Springer, Switzerland. 
1212 Tweti, M., 2008. Of parrots and people: the sometimes funny, always fascinating, and often 1213 catastrophic collision of two intelligent species. Viking, New York.

1214 van Hierden, Y., 2003. Behavioural neurobiology of feather pecking, University of Groningen, 1215 The Netherlands.

1216 van Hierden, Y.M., de Boer, S.F., Koolhaas, J.M., Korte, S.M., 2004a. The control of feather 1217 pecking by serotonin. Behav. Neurosci. 118, 575.

1218 van Hierden, Y.M., Koolhaas, J.M., Korte, S.M., 2004b. Chronic increase of dietary I1219 tryptophan decreases gentle feather pecking behaviour. Appl. Anim. Behav. Sci. 89, 71-84.

1220 van Hierden, Y.M., Koolhaas, J.M., Košt’ál, L.u., Výboh, P., Sedlačková, M., Rajman, M., 1221 Juráni, M., Mechiel Korte, S., 2005. Chicks from a high and low feather pecking line of laying 1222 hens differ in apomorphine sensitivity. Physiol. Behav. 84, 471-477. van Hierden, Y.M., Korte, S.M., Ruesink, E.W., van Reenen, C.G., Engel, B., Koolhaas, J.M., Blokhuis, H.J., 2002a. The development of feather pecking behaviour and targeting of pecking in chicks from a high and low feather pecking line of laying hens. Appl. Anim. Behav. Sci. $77,183-196$.

1227 van Hierden, Y.M., Korte, S.M., Ruesink, E.W., van Reenen, C.G., Engel, B., Korte-Bouws, G.A.H., Koolhaas, J.M., Blokhuis, H.J., 2002b. Adrenocortical reactivity and central serotonin and dopamine turnover in young chicks from a high and low feather-pecking line of laying hens. Physiol. Behav. 75, 653-659. van Hoek, C.S., King, C.E., 1997. Causation and influence of environmental enrichment on feather picking of the crimson-bellied conure (Pyrrhura perlata perlata). Zoo Biol. 16, 161172. 
van Hoek, C.S., Ten Cate, C., 1998. Abnormal behaviour in cages birds kept as pets. J. Appl. Anim. Welf. Sci. 1, 51-64.

van Horne, P., Achterbosch, T., 2008. Animal welfare in poultry production systems: impact of EU standards on world trade. World's Poultry Sci. J. 64, 40-52.

van Krimpen, M., Kwakkel, R., André, G., van der Peet-Schwering, C., den Hartog, L., Verstegen, M., 2007. Impact of nutritional factors on feather pecking behaviour of laying hens in non-cage housing systems, World Poultry Science Association, Proceedings of the 16th European Symposium on Poultry Nutrition, Strasbourg, France, 26-30 August, 2007, World's Poultry Science Association (WPSA), pp. 415-422.

van Krimpen, M., Kwakkel, R., van der Peet-Schwering, C., Den Hartog, L., Verstegen, M., 2009. Effects of nutrient dilution and nonstarch polysaccharide concentration in rearing and laying diets on eating behavior and feather damage of rearing and laying hens. Poultry Sci. $88,759-773$.

van Zeeland, Y.R., Schoemaker, N.J., 2014. Plumage disorders in psittacine birds-part 2: feather damaging behaviour. Eur. J. Companion Anim. Pract. 24, 24-36.

van Zeeland, Y.R.A., Schoemaker, N.J., Ravesteijn, M.M., Mol, M., Lumeij, J.T., 2013a. erithacus erithacus). Appl. Anim. Behav. Sci. 149, 87-102.

van Zeeland, Y.R.A., Spruit, B.M., Rodenburg, T.B., Riedstra, B., van Hierden, Y.M., 1253 Buitenhuis, B., Korte, S.M., Lumeij, J.T., 2009. Feather damaging behaviour in parrots: A 1254 review with consideration of comparative aspects. Appl. Anim. Behav. Sci. 121, 75-95. 
1257 (Psittacus erithacus erithacus) with and without feather damaging behaviour. Appl. Anim.

1258 Behav. Sci. 148, 218-231.

1259 Wang, S.-M., Kain, Z.N., White, P., 2008. Acupuncture analgesia: I. The scientific basis.

1260 Anesth. Analg. 106, 602-610.

1261 Wedel, A., 1999. Verhaltensstorungen, in: Wedel, A. (Ed.), Ziervogel-Erkrankungen,

1262 Haltung, Futterung, Parey Verlag im Blackwell Wissenschafts-Verlag,, Wien, pp. 283-286.

1263 Wickens, C.L., Heleski, C.R., 2010. Crib-biting behavior in horses: A review. Appl. Anim.

1264 Behav. Sci. 128, 1-9.

1265 Wiepkema, P.R., 1983. On the significance of ethological criteria for the assessment of 1266 animal welfare., In: Schmidt, D. (Ed.), Indicators Relevant to Farm Animal Welfare, Martinus 1267 Nijhoff, The Hague, pp. 71-79.

Wilson, D.A., Clark, A.B., Coleman, K., Dearstyne, T., 1994. Shyness and boldness in humans and other animals. Trends Ecol. Evol. 9, 442-446.

Wisely, J., Hare, D.J., Fernandez-Ford, L., 2002. A study of the topography and nature of self-injurious behaviour in people with learning disabilities. J. Intellect. Disabil. 6, 61-71.

1272 Würbel, H., Stauffacher, M., von Holst, D., 1996. Stereotypies in laboratory mice 1273 quantitative and qualitative description of the ontogeny of 'wire-gnawing' and 'jumping' in ICR and ICR nu - mice. Ethology 102, 371-385. 